\title{
Calcium Channels in Adult Brain Neural Stem Cells and in Glioblastoma Stem Cells
}

\author{
Valérie Coronas*, Elodie Terrié, Nadine Déliot, Patricia Arnault and Bruno Constantin \\ Laboratoire STIM, Université de Poitiers-CNRS ERL 7003, Poitiers, France
}

The brain of adult mammals, including humans, contains neural stem cells (NSCs) located within specific niches of which the ventricular-subventricular zone (V-SVZ) is the largest one. Under physiological conditions, NSCs proliferate, self-renew and produce new neurons and glial cells. Several recent studies established that oncogenic mutations in adult NSCs of the V-SVZ are responsible for the emergence of malignant primary brain

Edited by:

Francisco Javier Martin-Romero, University of Extremadura, Spain

Reviewed by:

Alejandro Berna,

University of Extremadura, Spain Artur Paasz,

Medical University of Silesia, Poland

*Correspondence: Valérie Coronas valerie.coronas@univ-poitiers.fr

Specialty section:

This article was submitted to Cellular Neuropathology, a section of the journal Frontiers in Cellular Neuroscience

Received: 28 August 2020 Accepted: 06 October 2020 Published: 13 November 2020

Citation:

Coronas V, Terrié E, Déliot N,

Arnault $P$ and Constantin $B$

(2020) Calcium Channels in Adult

Brain Neural Stem Cells and in

Glioblastoma Stem Cells.

Front. Cell. Neurosci. 14:600018. doi: 10.3389/fncel.2020.600018 tumors called glioblastoma. These aggressive tumors contain a small subpopulation of cells, the glioblastoma stem cells (GSCs), that are endowed with proliferative and self-renewal abilities like NSCs from which they may arise. GSCs are thus considered as the cells that initiate and sustain tumor growth and, because of their resistance to current treatments, provoke tumor relapse. A growing body of studies supports that $\mathrm{Ca}^{2+}$ signaling controls a variety of processes in NSCs and GSCs. $\mathrm{Ca}^{2+}$ is a ubiquitous second messenger whose fluctuations of its intracellular concentrations are handled by channels, pumps, exchangers, and $\mathrm{Ca}^{2+}$ binding proteins. The concerted action of the $\mathrm{Ca}^{2+}$ toolkit components encodes specific $\mathrm{Ca}^{2+}$ signals with defined spatio-temporal characteristics that determine the cellular responses. In this review, after a general overview of the adult brain NSCs and GSCs, we focus on the multiple roles of the $\mathrm{Ca}^{2+}$ toolkit in NSCs

\footnotetext{
Abbreviations: AMPA, $\alpha$-amino-3-hydroxy-5-méthylisoazol-4-propionate; $\mathrm{CaBP}, \mathrm{Ca}^{2+}$ binding protein; CaMK, $\mathrm{Ca}^{2+} /$ calmodulin-dependent protein kinase; CRAC, $\mathrm{Ca}^{2+}$ release activated $\mathrm{Ca}^{2+}$ channel; DAG, diacylglycerol; EGF, epidermal growth factor; ER, endoplasmic reticulum; GABA, gamma-aminobutyric acid; GFAP, glial fibrillary acidic protein; GPCR, G protein-coupled receptor; GSC, glioblastoma stem cell; IP3, inositol triphosphate; HDAC, histone deacetylase; IP3R, IP3 receptor; LGIC, ligand-gated ion channel; $\mathrm{MCU}$, mitochondrial $\mathrm{Ca}^{2+}$ uniporter; $\mathrm{nAChR}$, ionotropic cholinergic nicotinic receptors; NCX, $\mathrm{Na}^{+} / \mathrm{Ca}^{2+}$ exchanger; NFAT, nuclear factor activated T-cells; NMDA, N-methyl-Daspartate; NSC, neural stem cell; NTDPase, nucleoside triphosphate diphosphohydrolase; P2X, P2Y receptors, purinergic receptors; PIP2, Phosphatidylinositol 4, 5-bisphosphate; PLC, phospholipase C; PMCA, plasma membrane $\mathrm{Ca}^{2+}$ ATPase; RCAS-TVA, replication-competent avian sarcoma-leukosis virus (RCAS) and its receptor the tumor virus A (TVA); ROC, receptor-operated channel; ROCE, receptor-operated $\mathrm{Ca}^{2+}$ entry; RTK, receptor tyrosine kinases; RYR, ryanodine receptor; SDF1, stromal cell-derived factor 1; SERCA, sarco/endoplasmic reticulum $\mathrm{Ca}^{2+}$-ATPase; SOC, store-operated channel; SOCE, store-operated $\mathrm{Ca}^{2+}$ entry; STIM, stromal interaction molecule; TAP, transient amplifying progenitors; TRPC, transient receptor potential-canonical; TRPV, transient receptor potential vanilloid; VGCC, voltage-gated $\mathrm{Ca}^{2+}$ channels; V-SVZ, ventricular-subventricular zone.
} 
and discuss how GSCs hijack these mechanisms to promote tumor growth. Extensive knowledge of the role of the $\mathrm{Ca}^{2+}$ toolkit in the management of essential functions in healthy and pathological stem cells of the adult brain should help to identify promising targets for clinical applications.

Keywords: store-operated channel, calcium toolkit, neural stem cells, brain, glioma, glioblastoma, cancer stem cell, calcium channel

\section{INTRODUCTION}

In the brain of adult mammals, including humans, neural stem cells (NSCs) reside within two major regions: the ventricularsubventricular zone (V-SVZ, also called the subependymal zone or subventricular zone) lining the lateral brain ventricles and the subgranular zone of the dentate gyrus in the hippocampus. Within these niches, NSCs sustain lifelong neurogenesis and gliogenesis (Lim and Alvarez-Buylla, 2016; Lledo and Valley, 2016; Obernier and Alvarez-Buylla, 2019). In this review, we focus primarily on the $\mathrm{V}-\mathrm{SVZ}$ that is the largest germinal region of the adult brain. Within this neurogenic area, quiescent and activated NSCs coexist. Upon activation, NSCs divide to produce transient amplifying progenitors that engender neuroblasts that in turn, replenish the olfactory bulb population of interneurons. Adult NSCs in the V-SVZ also generate astrocytes and oligodendrocytes that disperse within the brain parenchyma (Lim and Alvarez-Buylla, 2016; Lledo and Valley, 2016; Obernier and Alvarez-Buylla, 2019).

While NSCs are mobilized by brain injuries and contribute to attempts of brain repair, recent studies have consistently established that oncogenic mutations in NSCs from the V-SVZ, unfortunately, lead to the development of glioblastoma, one of the deadliest cancers in adults (Recht et al., 2003; Barami, 2007; Quiñones-Hinojosa and Chaichana, 2007; Lee et al., 2018). These malignant tissues contain a subpopulation of cells, called glioblastoma stem cells (GSCs) that share several properties with NSCs from which they may derive (Recht et al., 2003; Zarco et al., 2019). Because of their growth properties and ability to resist the current treatments, GSCs are considered responsible for tumor initiation, growth, and relapse (Galli et al., 2004; Singh et al., 2004).

NSCs and GSCs are controlled by multiple extracellular signals, numbers of which recruit $\mathrm{Ca}^{2+}$ signaling actors to transduce their effects. $\mathrm{Ca}^{2+}$ is a ubiquitous second messenger that shapes a wide range of cellular functions including proliferation, migration, and cell differentiation in various cell types (Berridge et al., 2003). Increases of intracellular $\mathrm{Ca}^{2+}$ concentration are triggered by a variety of channels, transporters, and $\mathrm{Ca}^{2+}$-binding proteins (CaBP). These $\mathrm{Ca}^{2+}$ toolkit components encode specific $\mathrm{Ca}^{2+}$ signals that are defined by their spatio-temporal profile and their magnitude (Berridge, 1990; Berridge et al., 2003).

A growing bulk of evidence has pointed to a major role of $\mathrm{Ca}^{2+}$ in NSCs of the adult brain and in their pathological counterparts, namely GSCs. After a general overview of NSCs of the adult brain and on GSCs, we will review the progress that has been achieved on how $\mathrm{Ca}^{2+}$ signals regulate specific functions and properties of these cells. When appropriate, we put the data of the literature into the perspective of the development of treatments to combat brain diseases.

\section{ADULT BRAIN NEURAL STEM CELLS, NEUROGENESIS, AND PATHOLOGY}

\section{The Discovery of Neurogenesis and Neural Stem Cells in the Adult Brain}

Most adult organs retain a population of somatic stem cells that ensure tissue homeostasis and repair by producing new cells in response to physiological conditions or injury. The brain has long been considered an exception to this rule: it was widely assumed that neurogenesis occurred only during embryogenesis and early postnatal life and that only glial cells could be produced in adulthood. This dogma was first challenged in the 1960s by Joseph Altman who reported addition of new neurons in the olfactory bulb and hippocampus of adult rats, but experimental evidence obtained with the tools available at that time was not robust enough to counter the dogma stating that neurogenesis does not occur in adults (Altman, 1963, 1969; Altman and Das, 1965). With the emergence of new tools to label proliferating cells, the persistence of neurogenesis throughout life was then directly demonstrated in the brain of adult songbirds (Nottebohm, 1985), rodents (Luskin, 1993; Lois and Alvarez-Buylla, 1994), and non-human primates. In these latter, incorporation of new neurons was described not only in the hippocampus (Gould et al., 1998, 1999; Kornack and Rakic, 1999) and olfactory bulb (Kornack and Rakic, 2001) but also amygdala (Bernier et al., 2002). Since then, neurogenesis has been identified in other brain areas like the hypothalamus of rodent and sheep brains (Kokoeva et al., 2005; Migaud et al., 2010; Yoo and Blackshaw, 2018) and the dorsal vagal complex in rodents (Bauer et al., 2005). In 1998, the analysis of brain tissue obtained post-mortem from patients, who had been injected with the nucleotide analog bromodeoxyuridine (BrdU) for diagnostic purposes during their cancer treatment, established that new neurons are generated throughout the lifespan from dividing progenitor cells in the dentate gyrus of adult humans (Eriksson et al., 1998). This discovery settled the relevance of adult neurogenesis for humans and attracted interest in the field. A neurogenic activity in the human hippocampus and olfactory bulb as well as in the striatum, a structure adjacent to V-SVZ, has thereafter been confirmed by several studies, although some controversy persists concerning the addition of new neurons in the adult human brain (Bédard and Parent, 2004; Sanai et al., 2004; Spalding et al., 2013; Ernst et al., 2014; Boldrini et al., 2018; Kempermann et al., 2018; Sorrells et al., 2018). 
In parallel to the discovery of neurogenesis in the brain of adult mammals, cells with NSC properties were isolated by Reynolds et al. (1992) from adult mice brain and propagated in vitro. When placed in appropriate cell culture conditions, NSCs proliferate, forming structures called neurospheres, selfrenew, and subsequently give birth to neurons and glial cells (Figures 1A,B). Since this seminal work, NSCs have been obtained from a few adult rodent brain regions (including the hippocampus and the area postrema) of which the V-SVZ lining the brain lateral ventricles (LVs) contains the largest pool of dividing cells with defining characteristics of NSCs (Reynolds et al., 1992; Weiss et al., 1996; Palmer et al., 1997; Charrier et al., 2006). A decade later, Sanai et al. (2004) showed that V-SVZ harvested on post-mortem human brain contains multipotent NSCs that can be amplified in vitro and that retain the capacity to produce neurons and glial cells. Fueling considerable hope for stem cell-based brain therapies, these studies have been implemented by the demonstration of the possibility to harvest NSCs by endoscopy from human V-SVZ (Westerlund et al., 2005), which opens the opportunity to autologous cell transplantation and could help to circumvent the problems associated with the rejection of heterologous cell grafts.

\section{The V-SVZ Structure and Function}

The V-SVZ is a thin layer of cells extending along the walls of the LVs (Figures 2A,B). Combined immunocytochemical and ultrastructural characterization of the adult rodent V-SVZ enabled to recognize four main cell types within this germinal region: neuroblasts (Type A cells), SVZ astrocytes (Types B1 and B2 cells), immature precursors (Type C cells), and ependymal cells (Type E cells; Doetsch et al., 1997; Figure 2B). Ependymal cells form a single multiciliated layer that borders the LV and that contributes to the circulation of the cerebrospinal fluid flow. Type B cells possess ultrastructural and immunocytochemical staining characteristics of astrocytes, for example, GFAP (glial fibrillary acidic protein)-immunoreactivity, and express markers of immature cells such as SOX2 (Doetsch et al., 1997). Type B cells have been further subdivided into type B1 and type B2 cells based on their localization within the V-SVZ and cellular properties. Multiple lineage-tracing studies consistently identified type B1 cells as the NSC population (Doetsch et al., 1999a; Imura et al., 2003; Garcia et al., 2004). These cells display a radial morphology, have a short apical process with a single primary cilium sent into the LV, and extend a long basal process ending on blood vessels (Mirzadeh et al., 2008). The primary cilium, which is exquisitely poised to sense molecular signals and the mechanical flow of the cerebrospinal fluid, contributes to controlling NSC activation (Tong et al., 2014). In adult mice, there are roughly 6,000 B1 cells on the lateral wall of the LVs (Mirzadeh et al., 2008). NSCs can shuttle between activity (B1a) and quiescence (B1q), a process that is regulated by the signals arriving on NSCs. When activated, type B1 cells divide slowly, self-renew and give rise to type $\mathrm{C}$ cells that act as transient amplifying progenitors and express immature markers like nestin (Doetsch et al., 1999b; Figure 2D). For cell proliferation, NSCs can undergo three modes of division (Figure 1C): asymmetric divisions produce both a stem cell and a progenitor and thus couple NSC pool maintenance to neurogenic activity, symmetric proliferative divisions engender two NSCs, and symmetric differentiative divisions generate two progenitor cells. Analysis of NSC mode of division established that they mostly divide by symmetric divisions to either self-renew or produce differentiated progenies, indicating that neurogenesis and self-renewal might be independently regulated in the V-SVZ (Obernier et al., 2018). Type B2 cells have been poorly studied but a recent publication proposed that they may be produced by type B1 cells and serve as a reserve population of NSCs (Obernier et al., 2018). Type C cells divide rapidly and generate neuroblasts (type A cells; Figures 2B,D) that also undergo one or two rounds of cell division to further amplify the number of new neurons engendered (Ponti et al., 2013). Neuroblasts produced in the $\mathrm{V}$-SVZ migrate for a long distance in aggregates forming tangentially oriented chains that coalesce into a defined pathway, the so-called rostral migratory stream (RMS; Figure 2A; Lois and Alvarez-Buylla, 1994; Lois et al., 1996). After about 5 days, neuroblasts reach the core of the olfactory bulb, detach from the chains and start to migrate radially towards their final location within the olfactory bulb (Petreanu and Alvarez-Buylla, 2002). Then, they differentiate as local interneurons that integrate the pre-existing neuronal network and contribute to olfactory processing and memory (Gheusi et al., 2000; Petreanu and Alvarez-Buylla, 2002; Tepavčević et al., 2011; Alonso et al., 2012; Gheusi and Lledo, 2014). In young adult mice, it has been estimated that NSCs produce approximately 10,000 young migrating neuroblasts every day (Doetsch et al., 1999b). NSCs also generate oligodendrocytes that join neighboring corpus callosum, striatum, and fimbriafornix both in physiological conditions and after demyelination (Menn et al., 2006; Nait-Oumesmar et al., 2007; Ortega et al., 2013; Capilla-Gonzalez et al., 2014b). Although NSCs sustain lifelong neurogenesis and gliogenesis, it remains unknown whether individual NSCs are multipotent in vivo or whether neurons and glia arise from distinct NSCs (Menn et al., 2006; Capilla-Gonzalez et al., 2013; Ortega et al., 2013; Sohn et al., 2015).

The V-SVZ of adult humans is mainly similar to the V-SVZ of rodents described above but differs by its organization in four layers (Quiñones-Hinojosa et al., 2006; Figure 2C). Layer $\mathrm{I}$ is a monolayer of ependymal cells that border the ventricular lumen. This layer is followed by a hypocellular layer (Layer II), heavily populated with processes of astrocytes that are joined to each other by gap junctions and large desmosomes (Quiñones-Hinojosa et al., 2006). A dense ribbon of cell bodies, many of which belong to astrocytes form layer III, lies next to layer II. Some of these astrocytes proliferate and behave as multipotent stem cells (type B cells) when placed in vitro (Sanai et al., 2004; Quiñones-Hinojosa et al., 2006). Some isolated neuroblasts (type A cells) are also found within this layer as well as in layers II and IV, the latter being a transition layer with the brain parenchyma (Sanai et al., 2004; Macas et al., 2006; Curtis et al., 2007; Wang et al., 2011). The V-SVZ of children younger than 18 months of age harbors many neuroblasts migrating along specific pathways to integrate as neurons not 

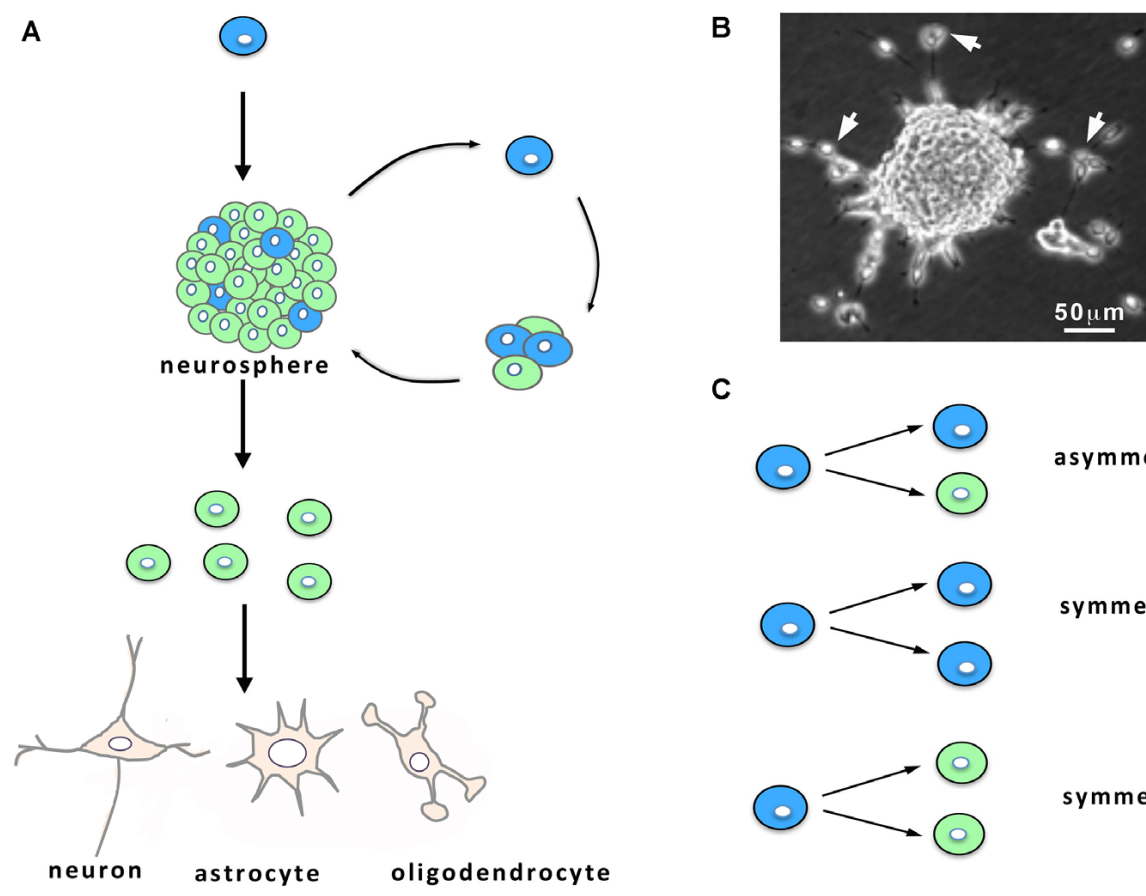

C

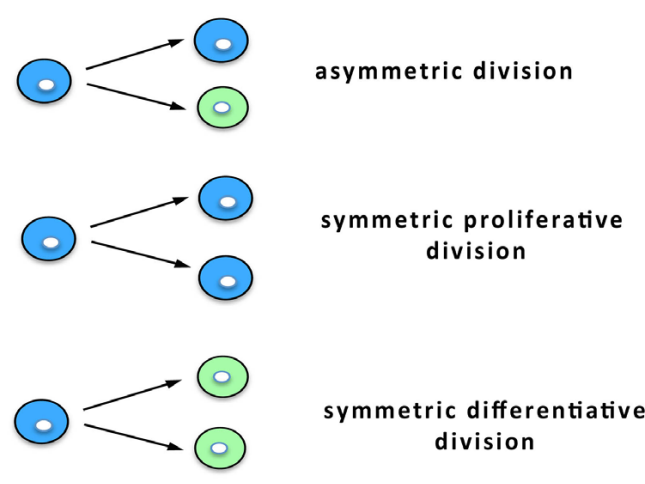

FIGURE 1 | Characteristics of neural stem cell (NSC) cultures. (A) When maintained in vitro in the presence of growth factors, NSCs (in blue) from the ventricular-subventricular zone (V-SVZ) proliferate and give birth to both NSCs and progenitors (in green) that engender differentiated cells, namely neurons, astrocytes and oligodendrocytes. Within the cultures, the progenies derived from the NSC remain together and form neurospheres (A,B) from which can emerge following 1 week in vitro some migrating neuroblasts. (B) Micrograph of a culture showing a neurosphere and migrating neuroblasts (arrows). (C) NSC division: NSCs can undergo either asymmetric cell divisions, giving birth to a NSC (in blue) and a progenitor (in green), or symmetric proliferative cell divisions, engendering two NSCs, or symmetric differentiative cell divisions, leading to two progenitors.

only into the olfactory bulb but also into the ventral medial prefrontal cortex or the frontal lobe (Sanai et al., 2011; Paredes et al., 2016). This process has been reported to decline sharply during infancy (Sanai et al., 2011; Paredes et al., 2016). By adulthood, the existence of migrating neuroblasts along a RMS and incorporation of new neurons in the human olfactory bulb seems nearly extinct although there are conflicting results providing evidence of a maintenance neurogenic activity in the V-SVZ of the adult human brain (Curtis et al., 2007; Sanai et al., 2011; Wang et al., 2011; Paredes et al., 2016). One of the major hurdles when examining neurogenesis on post-mortem human brains is the possibility of labeling newly born cells. To circumvent this setback, the group led by Frisen measured ${ }^{14} \mathrm{C}$ incorporated in neurons of post-mortem human brains to evaluate the numbers of newly incorporated cells in the adult brain. These studies are based on the fact that nuclear bomb testing during the Cold War in the 1950s produced elevated levels of ${ }^{14} \mathrm{C}$ in the atmosphere, which entered the biotope and thereby, was incorporated in human molecules, including nucleotides forming DNA. It is assumed that the level of ${ }^{14} \mathrm{C}$ in $\mathrm{DNA}$ mirrors the level of ${ }^{14} \mathrm{C}$ at any given time, allowing the birthdate of cells in the human body to be determined retrospectively. This approach combined with histological studies showed that, in the adult human brain, V-SVZ neuroblasts robustly supply the adjacent striatum with new interneurons and also, generate new oligodendrocytes
(Bergmann et al., 2012; Ernst et al., 2014). Altogether, these data support that the V-SVZ of the adult human brain contains NSCs whose implication in neurogenesis and gliogenesis in vivo requires further investigation in humans.

The NSCs and their activity are substantially affected by aging. Concretely, shrinkage of the pool of the V-SVZ NSCs occurs with age (Maslov et al., 2004; Shook et al., 2012; Kalamakis et al., 2019). This smaller stem cell reservoir seems to display a decreased proliferative activity (Bouab et al., 2011; Capilla-Gonzalez et al., 2014a; Kalamakis et al., 2019), although some reports indicated the opposite (Ahlenius et al., 2009; Shook et al., 2012). A recent study based on fluorescenceactivated cell sorting (FACS) analysis and injury-induced regeneration experiments in mice nicely demonstrated that quiescent NSCs in the old brain are resistant to activation but, when activated, NSCs exhibit similar behavior in the brains of young and old mice (Kalamakis et al., 2019). This increase in quiescence during aging would allow protecting the stem cell reservoir from full depletion but makes old NSCs more resistant to regenerate the injured brain. Despite age-induced quiescence in NSCs, an increase in the number of progenitors has been reported in the aged adult human forebrain following ischemia, suggesting that NSCs, at least the active subpopulation of NSCs, might be recruited by injuries in the elderly (Macas et al., 2006). In addition to inducing a state of quiescence, aging also modifies the fate 
A

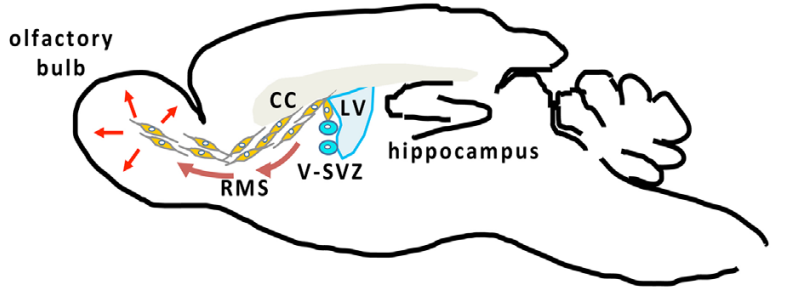

B Mouse

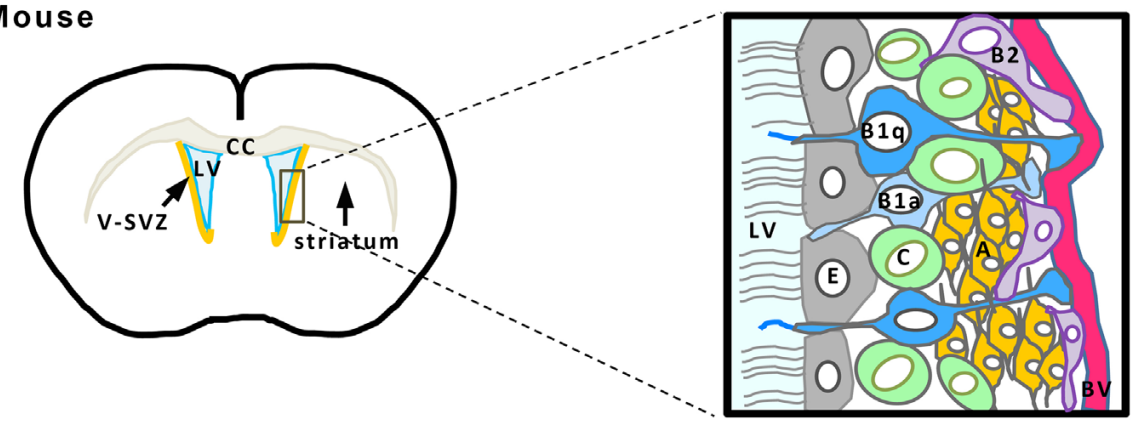

C Human

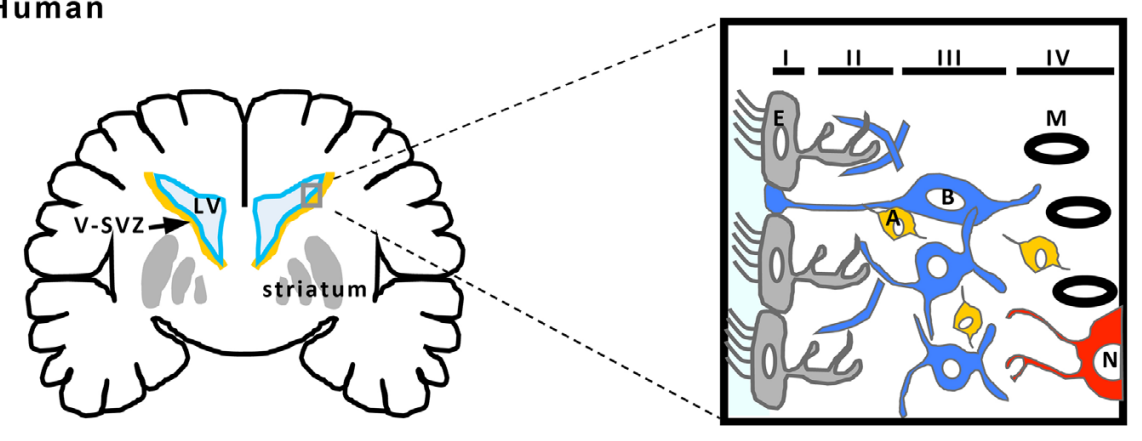

D

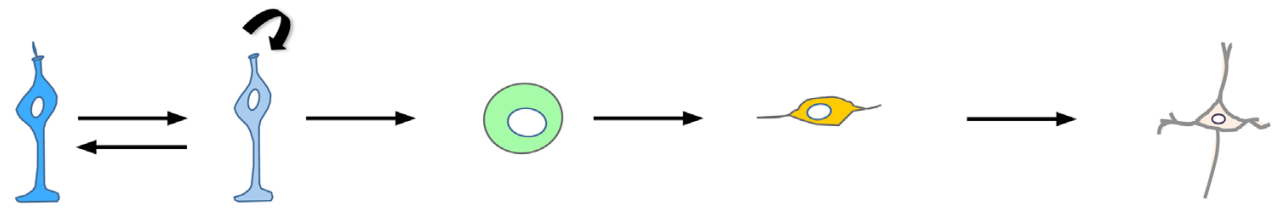

quiescent NSC

active NSC

TAP (C cell)

Neuroblast (A cell)

Neuron

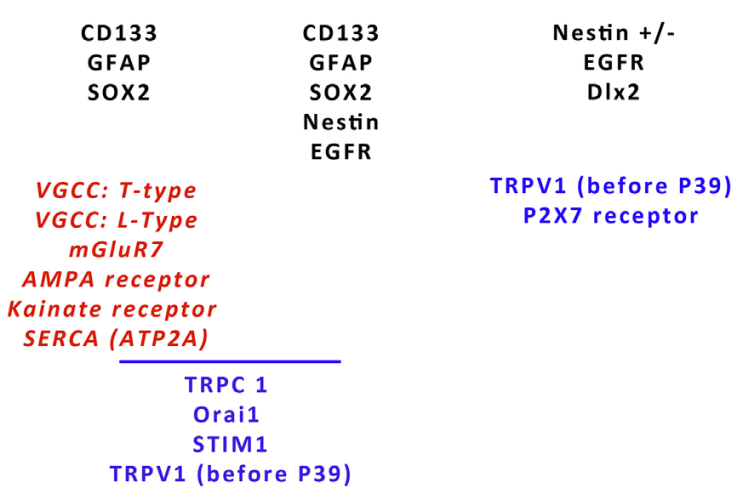
Nestin +/-
PSA-NCAM
DCX

$\beta$ III tubulin

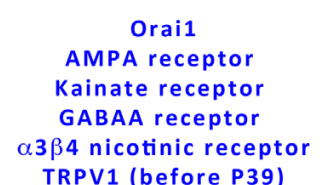

TRPV1 (before P39)

FIGURE 2 | Cellular organization of the V-SVZ. (A) Sagittal view of the mouse brain showing the V-SVZ that borders the brain lateral ventricle (LV). The V-SVZ contains NSCs (in blue) producing neuroblasts (in orange) that migrate tangentially along the rostral migratory stream (RMS) to join the olfactory bulb where they integrate the existing network. CC, Corpus callosum. Frontal sections (on the left) of the mouse (B) and the human (C) brains represent the V-SVZ that borders the LVs. The square delineates the zone enlarged illustrating a schema of the organization of the V-SVZ (on the right). (B) (mouse brain) Ependymal cells (E, in gray) 
FIGURE 2 | Continued

border the LV. NSCs (B1 cells in blue; B1a: active B1 cells; B1q: quiescent $\mathrm{B} 1$ cells) are located just beneath the ependymal layer and extend a cilium in the LV and a process that contacts a blood vessel (BV, in red). B1 cells can give birth to B2 cells (purple) that may act as NSC reserve cells. B1 cells engender transient amplifying progenitors (C cells, in green) that give birth to neuroblasts (A cells, in orange), then differentiating as neurons in the olfactory bulb. (C) In human brain, the V-SVZ is organized in four layers. Layer I is formed of ependymal cells (E, in gray). Layer II is a hypocellular layer with mainly processes. Layer III contains the cell bodies of astrocytes, part of which are NSCs (B cells, in blue). Layer IV is a transition layer with the parenchyma where myelin ( $\mathrm{M}$ in black) and neurons ( $\mathrm{N}$, in red) can also be found. NSCs produce some neuroblasts (A cells, in orange) that are found across layers II to IV. (D) The different stages of adult neurogenesis from B cells to differentiated neurons. B cells (in blue) are NSCs that can shuttle between a quiescent and an active state. Neurogenesis occurs when $B$ cells give birth to $C$ cells that engender $A$ cells migrating towards the olfactory bulb and then, differentiating as neurons. On the schema, characteristic markers expressed by the different cell types of the SVZ are indicated in black below each cell. The different components of the $\mathrm{Ca}^{2+}$ toolkit expressed within each of the cells are given below the corresponding cell. For B cells, some transcriptomic studies have highlighted the expression of specific components in quiescent cells. When the only information available concerns RNA expression, the corresponding actors are written in red, otherwise they are in blue. This figure has been elaborated according to the following references: Nguyen et al. (2003), Platel et al. (2008), Khodosevich et al. (2009), Young et al. (2010), Daynac et al. (2013), Sharma (2013), Khatri et al. (2014), Somasundaram et al. (2014), Stock et al. (2014), Domenichini et al. (2018), and Leeson et al. (2018).

of the cells generated by NSCs, with a substantial reduction in the production of new neurons, whereas the genesis of oligodendroglial cells is unaffected in the aged brain (Ahlenius et al., 2009; Shook et al., 2012; Capilla-Gonzalez et al., 2013, 2015). Although the consequences of these alterations need further exploration, several reports suggest that impaired NSC activity may be associated with age-related diseases (Demars et al., 2010; Lazarov and Marr, 2013).

\section{Recruitment of Adult Brain Neural Stem Cells by Brain Pathologies}

In addition to maintaining tissue homeostasis, somatic stem cells are defined by their ability to respond to lesions. In this regard, several studies disclosed that NSCs from the $\mathrm{V}-\mathrm{SVZ}$ are recruited by various brain lesions including stroke and brain trauma, or by degenerative diseases (GonzalezPerez, 2012; Beckervordersandforth and Rolando, 2019; Bacigaluppi et al., 2020). To illustrate this concept, we chose to focus on two specific brain injuries: stroke, that is the second leading cause of death and the third leading cause of disability according to the World Health Organization, and multiple sclerosis, that is one of the most widespread disabling neurological condition of young adults around the world.

A stroke occurs when the blood flow to the brain is disrupted because of occlusion or rupture of a cerebral artery. Ischemia, caused by blockage of an artery, is the most common form of stroke. It leads to irreversible injury in the core region and partially reversible damage in the surrounding penumbra zone that has been deprived of blood supply. Stroke induction by transient middle cerebral artery occlusion, the most common model used for research in rodents, has been reported to boost cell proliferation in the V-SVZ by triggering NSC activation and to provoke the migration of neuroblasts from the $\mathrm{V}-\mathrm{SVZ}$ towards the damaged areas (Arvidsson et al., 2002; Parent et al., 2002; Jin et al., 2003; Zhang et al., 2004). In the injured striatum, the neuroblasts arising from the V-SVZ differentiated as mature neurons, but $80 \%$ of the stroke-generated striatal neurons died during the first 2 weeks after their formation, which resulted in a very weak replacement of the striatal neuronal population lost due to the injury (Arvidsson et al., 2002). Although disappointing from a clinical perspective, these data point to the fact that NSCs contribute to attempts at brain repair. Furthermore, the fact that specific ablation of migrating neuroblasts in transgenic mice models resulted in increased infarct size and worsened functional recovery strongly suggests that stroke-recruited neuroblasts may help brain healing through mechanisms that are still elusive (Jin et al., 2010; Sun et al., 2012). It may be interesting to mention here that recent demonstrations of the ability of NSCs and neuroblasts to remove dead cell debris through phagocytosis raise a possible role of these cells in clearing the diseased environment, although this hypothesis needs to be experimentally challenged (Lu et al., 2011; Ginisty et al., 2015). Besides, NSC activation and an increase in the number of neuroblasts close to the lateral ventricular walls have also been described in brains of patients with ischemia, even those of advanced age (up to 80 years; Jin et al., 2006; Macas et al., 2006; Martí-Fàbregas et al., 2010). These results suggest that, in humans, the adult brain NSCs retain a capacity to respond to ischemic injuries and that this capacity is maintained in old age.

Multiple sclerosis is a chronic, autoimmune, and demyelinating disease that affects the central nervous system, especially among young individuals. In this pathology, most patients initially develop a clinical pattern with periodic relapses followed by remissions that ultimately end in permanent neurological disability. Experimental rodent models of demyelination displayed increased cell proliferation and migration of V-SVZ progenitors into the injured white matter where many of the mobilized cells differentiated as oligodendrocytes, in response to demyelination (Picard-Riera et al., 2002). Consecutive lineage tracing studies confirmed that V-SVZ cells, in addition to resident parenchymal oligodendroglial precursors, efficiently produce new oligodendrocytes with robust capacities of remyelination (Xing et al., 2014; Brousse et al., 2015). However, a recent study reported that selective ablation of V-SVZ cells although resulting in lowered oligodendrogenesis in mice models with multiple sclerosis, did not impact the ensuing remyelination but enhanced axonal loss (Butti et al., 2019), suggesting that NSCs may exert their beneficial effects either through oligodendrocyte replacement, or by providing trophic support, or both. In the human brain, NSC recruitment and oligodendrogenesis were also found in post-mortem brains of patients with multiple sclerosis and, importantly, were shown to occur in the brains of elderly patients (Nait-Oumesmar et al., 2007; Snethen et al., 2008). Interestingly, the olfactory dysfunction observed in mice 
models of multiple sclerosis and related to the reduced supply of olfactory bulb neurons was also described in patients, suggesting that at least part of the mechanisms identified in mice may occur in humans (Tepavčević et al., 2011).

\section{Adult Neural Stem Cell Relationship With Cancer Stem Cells in Brain Tumors}

Glioblastoma is the most frequent of primary brain tumors and among the most refractory of malignancies. Standard treatment includes gross total surgical resection followed by concurrent radiotherapy and chemotherapy with the drug temozolomide (Stupp et al., 2005). Because of the resistance of glioblastoma to the current treatments, the median survival of patients hardly reaches 15 months from the time of the diagnosis (Stupp et al., 2005). Thus, new means of eliminating these tumoral cells are keenly awaited. In the process of improving the understanding of glioblastoma growth and recurrence, a subpopulation of tumor cells, called GSCs, was identified as the cause of tumor initiation, resistance to current therapies, and thus, disease recurrence (Singh et al., 2004; Bao et al., 2006; Chen et al., 2012; Chesnelong et al., 2019). The cancer stem cell hypothesis states that tumors mimic normal tissues with hierarchically arranged populations of cells, with cancer stem cells at the apex that are endowed with regenerative potential and with the ability to provide all the functional diversity of the original tumor (Figure 3). As they are more quiescent than the other tumoral cells, cancer stem cells survive the current treatments that target highly proliferative cancer cells, and then, rebuild the tumor after the treatment, provoking cancer relapse in the patient.

Because GSCs share several properties with NSCs, the hypothesis that they may derive from NSCs has been explored (Figure 3). In the 1960s, it was reported that the offspring of pregnant rats, exposed to a single injection of the mutagenic molecule $N$-Ethyl- $N$-Nitrosourea during late gestation, developed spontaneous glioblastoma when they were 4-months-old. These animals displayed early neoplasia in the V-SVZ several weeks before macroscopic tumors were noted, suggesting that glioblastoma may originate in the V-SVZ germinal niche (Recht et al., 2003). The advent of genetic tools to specifically transfer oncogenes or to inhibit tumorsuppressors in vivo in NSCs of transgenic mice made it possible to assess and substantiate the idea that NSCs represent possible cells of origin of glioblastoma. To selectively infect NSCs, Holland and colleagues took advantage of the RCAS-TVA viral system to target nestin-positive stem cells in vivo. In this approach, the gene coding for avian retrovirus receptor TVA is placed under the control of the nestin promoter which leads to an expression of TVA selectively in nestin-positive cells in the transgenic mice, allowing thereafter transduction of dividing nestin-positive cells with the avian retrovirus RCAS through its receptor TVA. The introduction of an RCAS viral vector containing the oncogenic forms of both Ras and Akt in these transgenic neonatal mice resulted in the spontaneous onset of high-grade glioma (Holland et al., 2000). About a decade later, Marumoto et al. (2009) confirmed that targeting oncogenic mutations in NSCs of the V-SVZ leads to the development of glioblastoma. To this end, they took advantage of the cre/lox system to drive the expression of oncogenic Ras or Akt specifically in GFAP-expressing cells of the V-SVZ. For that purpose, they injected lentiviral vectors encoding of oncogenic Ras or Akt with expression controlled by cre recombinase in the $\mathrm{V}-\mathrm{SVZ}$ of adult immunocompetent mice, heterozygous for p53 and genetically engineered to have a GFAP-driven expression of the recombinase cre. In these mice, the cre-induced expression of oncogenic Ras or Akt in GFAP-positive cells of the V-SVZ provoked the development of high-grade glioma (Marumoto et al., 2009). This study moreover underlined that infection of as few as 60 GFAP-expressing cells in the V-SVZ was sufficient to induce the emergence of a full-blown tumor containing GSCs whereas glioblastoma rarely developed when GFAP-expressing non-stem cells from the cortex were transduced (Marumoto et al., 2009). Concomitant studies corroborated that introduction of glioblastoma-specific oncogenic mutations in NSCs of the V-SVZ lead to a spontaneous tumoral development with a $100 \%$ penetrance (Alcantara Llaguno et al., 2009; Jacques et al., 2010). Altogether, these data consistently support that high-grade glioma originates from NSCs of the V-SVZ that have undergone malignant transformation although a few reports have identified more differentiated cells as an alternative source of cells at the origin of glioblastoma (Lindberg et al., 2009; Liu et al., 2011; Friedmann-Morvinski et al., 2012).

Recently, a study based on deep-sequencing analysis of brain tissues provided evidence that oncogenic mutations in the V-SVZ are responsible for the development of high-grade glioma in humans (Lee et al., 2018). The publication reports that, in more than half of the human brains examined, normal SVZ tissue away from the tumor contained low-level cancerderiving mutations in genes such as TP53, PTEN, EGFR, and TERT promoter, that were similar to those found in their matching tumors (Lee et al., 2018; Matarredona and Pastor, 2019). Furthermore, the authors described that NSCs from the V-SVZ carrying driver mutations were able to migrate from the SVZ and to form high-grade malignant gliomas in distant brain regions, clearly suggesting an ontogenetic link between NSCs from the V-SVZ and glioblastoma that has been confirmed by other studies (Garcia and Dhermain, 2018; Lee et al., 2018; Tejada Neyra et al., 2018). Accordingly, it is currently admitted that cell-autonomous changes in NSCs of the V-SVZ germinal zone are most likely responsible for the emergence of glioblastoma and that NSCs could represent the cells of origin of GSCs, which matches actual demographic data on glioma incidence in the human population (Bauer et al., 2014).

In addition to this ontogenetical relationship between NSCs and GSCs, direct interactions between NSCs and the tumor have been found. It was discovered in experimental mice models of glioma that NSCs are endowed with a tumor tropism that allows them to track tumor cells and circumscribe the tumor mass, overall leading to an oncostatic effect and improved survival of mice bearing the tumor (Glass et al., 2005). This innate tumor tropism of NSCs for glioblastoma is currently exploited in clinical trials using genetically engineered therapeutic NSCs to deliver 


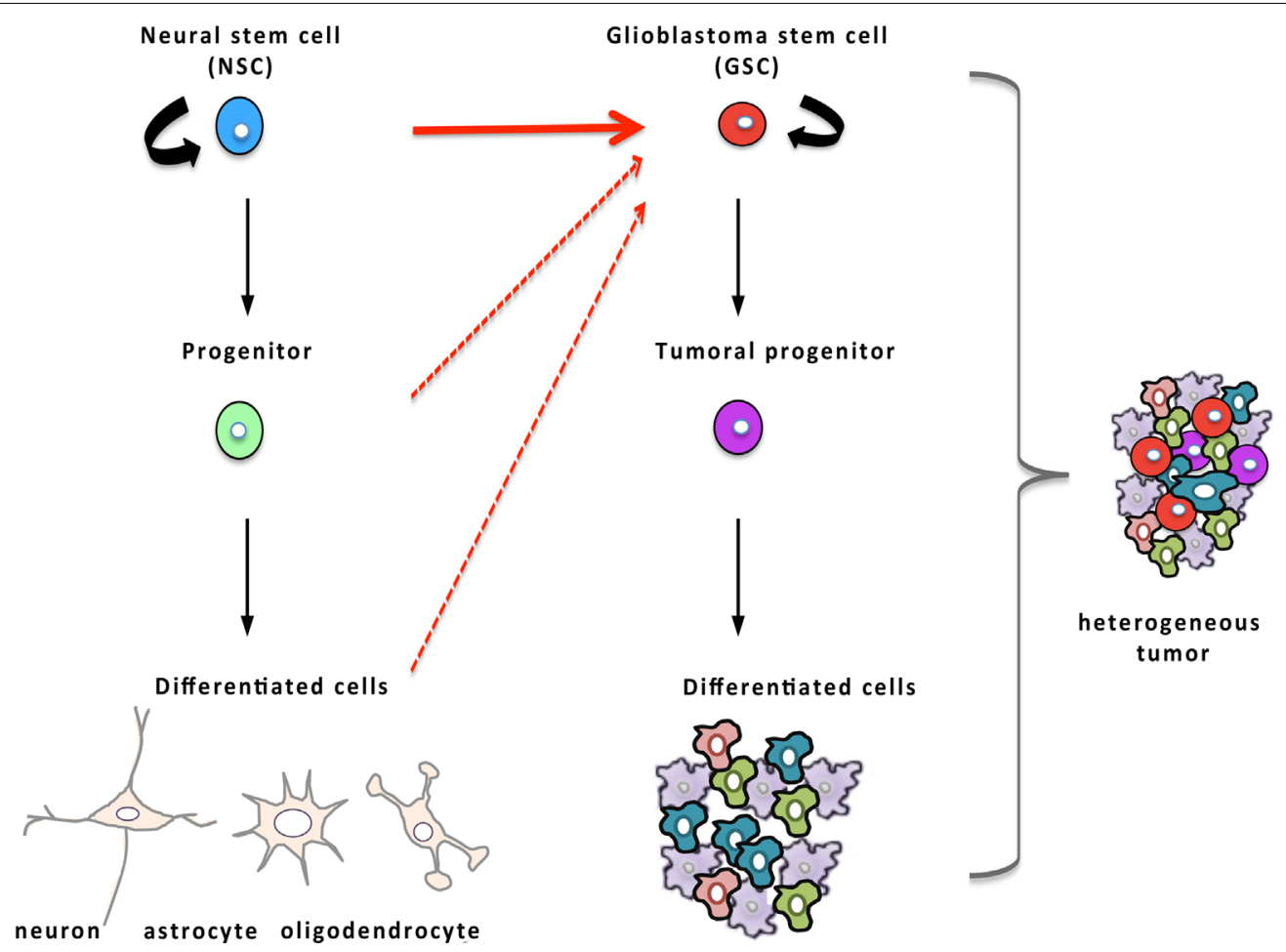

FIGURE 3 | Glioblastoma stem cells (GSCs) and their relationship to NSCs. Hierarchical organization of tumors that, by analogy with NSCs (in blue) of the normal tissue displayed on the left part of the figure, possess, at the apex, GSCs (in red) endowed with the regenerative potential and capable of producing more differentiated tumor cells and recapitulating tumor heterogeneity. Compelling evidence established that oncogenic mutations in NSCs are responsible for the emergence of GSCs (red arrow) although some data suggest that GSCs may also arise from more differentiated cells (dashed red arrows).

cytotoxic drugs specifically to the tumor site (Portnow et al., 2017; Gutova et al., 2019).

\section{THE CALCIUM TOOLKIT}

NSCs and GSCs, like the other cells of the organism, evolve in specific microenvironments whose signals shape their activities in response to the physiological demand or the pathological growth. Numerous microenvironmental signals transduce their effects through transitory rises of intracellular concentration of $\mathrm{Ca}^{2+}$ with specific durations and magnitudes, either in discrete cellular microdomains or throughout the whole cell (Berridge et al., 2003). Because of its wide repertoire of spatio-temporal variations in its intracellular concentrations, the $\mathrm{Ca}^{2+}$ signal is ideally poised to determine cellular processes in response to extracellular signals. Consequently, strict handling of $\mathrm{Ca}^{2+}$ is required to maintain optimized cellular functions. $\mathrm{Ca}^{2+}$ fluctuations are managed by different molecules that can be subdivided as follows: $\mathrm{Ca}^{2+}$ permeable channels that flux $\mathrm{Ca}^{2+}$ into the cell through the plasma membrane or that release $\mathrm{Ca}^{2+}$ from internal stores of the endoplasmic reticulum (ER) and mitochondria, $\mathrm{Ca}^{2+}$ pumps and exchangers that replenish $\mathrm{Ca}^{2+}$ stores or that extrude $\mathrm{Ca}^{2+}$ from the cell, and CaBP that buffer cytosolic free $\mathrm{Ca}^{2+}$ or act as effectors. The coordinated action of the $\mathrm{Ca}^{2+}$ toolkit components maintains low resting levels of cytosolic free $\mathrm{Ca}^{2+}$ and encodes specific $\mathrm{Ca}^{2+}$ signals that trigger selective cellular activities in response to extracellular signals (Berridge et al., 2003). While the $\mathrm{Ca}^{2+}$ signal is ubiquitously used to transduce extracellular signals, the proteins that control $\mathrm{Ca}^{2+}$ transport display cell type-specific expression, allowing selective cellular responses. Compelling evidence suggests that $\mathrm{Ca}^{2+}$ channels play a pivotal role in tumor biology, display aberrant expression or localization and that they are hijacked to promote tumor growth and resistance to treatment (Déliot and Constantin, 2015; Prevarskaya et al., 2018; Terrié et al., 2019). Figure 4 shows an overview of the key components of the $\mathrm{Ca}^{2+}$ toolkit. Here below, we provide a short description of this toolkit.

\section{Plasma Membrane Channels}

At rest, the cytosolic concentration of $\mathrm{Ca}^{2+}$ is maintained at very low levels (50-100 nmol/L), which is about 10,000-fold less than those of the extracellular medium. Thus, the opening of any $\mathrm{Ca}^{2+}$ channel located in the plasma membrane leads to a pronounced $\mathrm{Ca}^{2+}$ influx that sharply raises the intracellular $\mathrm{Ca}^{2+}$ concentration, that in turn, affects the activity of nearby proteins and elicits biological responses (Samanta and Parekh, 2017). $\mathrm{Ca}^{2+}$ inflow from the external milieu is controlled by a variety of transmembrane proteins, of which $\mathrm{Ca}^{2+}$ channels mediate $\mathrm{Ca}^{2+}$ entry from an extracellular compartment in response to diverse stimuli: membrane depolarization, extracellular agonists, 


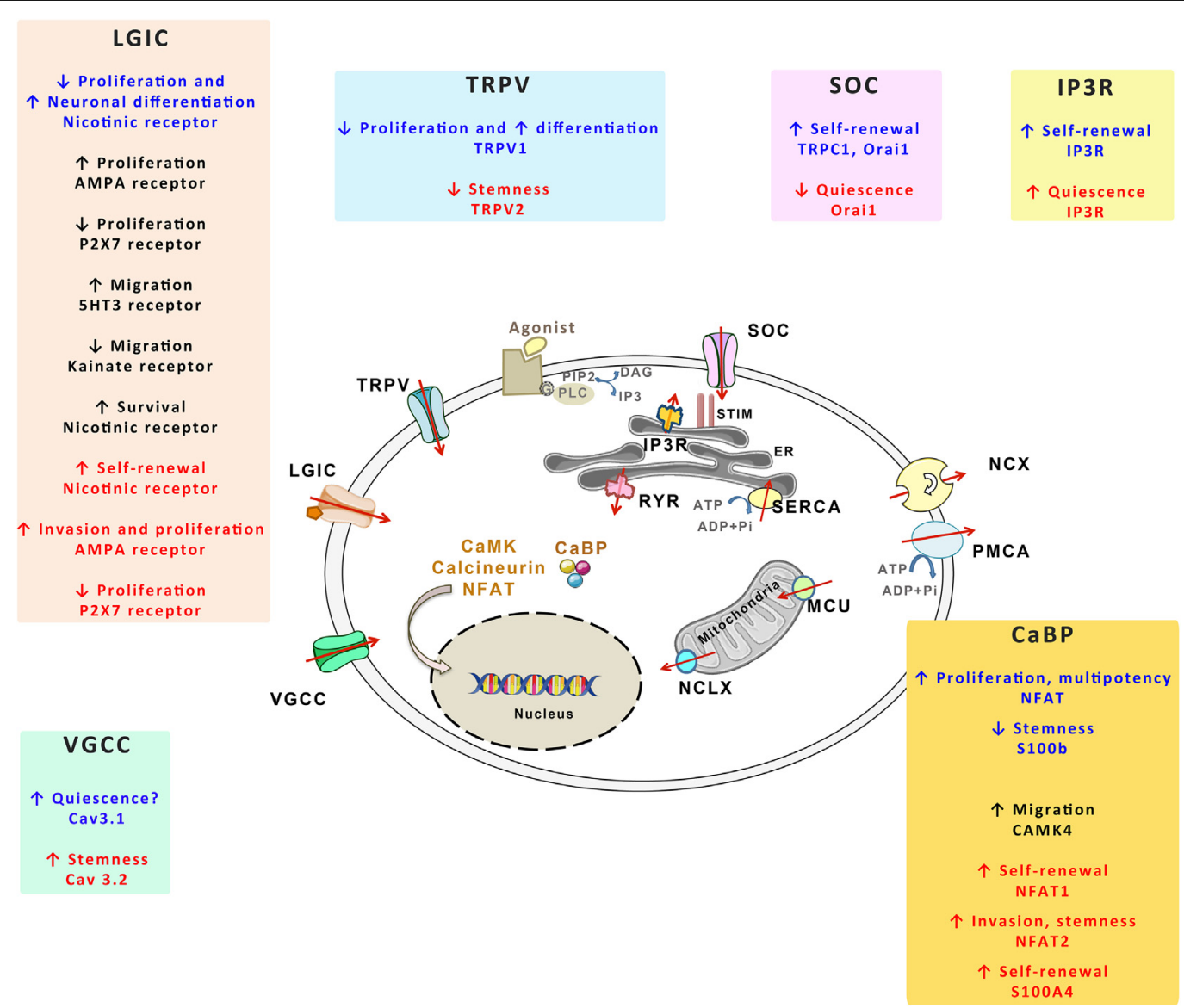

FIGURE 4 | The $\mathrm{Ca}^{2+}$ toolkit in NSCs and GSCs. The figure summarizes the different components of the $\mathrm{Ca}^{2+}$ toolkit. The red arrows represent the $\mathrm{Ca}^{2+}$ flux. Plasma membrane channels include voltage-gated $\mathrm{Ca}^{2+}$ channels (VGCCs), ligand-gated ion channels (LGICs), transient receptor potential vanilloids (TRPVs) and store-operated channels (SOCs). Plasma membrane also contains $\mathrm{Ca}^{2+}$-extruding mechanisms, namely $\mathrm{Na}^{+} / \mathrm{Ca}^{2+}$ exchanger $(\mathrm{NCX})$ and plasma membrane $\mathrm{Ca}{ }^{2+}$ ATPase (PMCA). Within the endoplasmic reticulum (ER), both IP3 receptor (IP3R) and ryanodine receptor (RYR) allow Ca ${ }^{2+}$ release in the cytosol whereas sarco/endoplasmic reticulum $\mathrm{Ca}^{2+}$-ATPase (SERCA) replenishes ER $\mathrm{Ca}^{2+}$ stores. STIM1 detects ER $\mathrm{Ca}^{2+}$ concentrations that activate SOC. Mitochondria release or take up $\mathrm{Ca}^{2+}$ respectively through mitochondrial $\mathrm{Na}+/ \mathrm{Ca}^{2+}$ exchanger (NCLX) and mitochondrial $\mathrm{Ca}^{2+}$ uniporter (MCU). The cells also contain $\mathrm{Ca}^{2+}$ binding protein (CaBP) that act as $\mathrm{Ca}^{2+}$ buffers or that transduce $\mathrm{Ca}^{2+}$ signals (calcineurin, NFAT, CaMK). GPCR corresponds to G protein coupled receptors, PLC to phospholipase C. For each of these $\mathrm{Ca}^{2+}$ actors, their effects on NSCs (written in blue), on the progenies of NSCs (written in black) and on GSCs (written in red) are provided within the specific insets.

intracellular messengers, mechanical stretch, or depletion of intracellular $\mathrm{Ca}^{2+}$ stores (Berridge et al., 2003).

\section{Voltage-Gated Calcium Channels (VGCCs)}

VGCCS also called voltage-operated calcium channels (VOCC) mediate $\mathrm{Ca}^{2+}$ influx in cells in response to membrane depolarization. An initial increase of the membrane potential is required for the activation of the intrinsic voltage sensor and subsequent pore opening. VGCCs comprises ten members, based on the expression of a specific pore-forming $\alpha_{1}$-subunit containing the voltage sensor of the Cav family channels. This family has been subdivided into three phylogenetic subfamilies according to the characteristics of the currents they mediate: $\mathrm{Ca}_{\mathrm{V}} 1$ subfamily channels that give rise to L-Type currents, $\mathrm{Ca}_{\mathrm{V}} 2$ subfamily channels that produce to $\mathrm{P} / \mathrm{Q}-, \mathrm{N}$-, and R-type currents, and $\mathrm{Ca}_{\mathrm{V}} 3$ subfamily channels that mediate T-type currents (Catterall et al., 2005; Catterall, 2011). L-type and
T-type $\mathrm{Ca}_{V}$ subfamilies are expressed in many cell types while $\mathrm{N}, \mathrm{P} / \mathrm{Q}$, and R-type channels are predominantly expressed in neurons. VGCCs have been first studied in electrically excitable cells, but it is now clear that they are functionally expressed in non-excitable cells including various cancer cell types (Prevarskaya et al., 2010, 2018).

\section{Receptor-Operated Channels (ROCs) and Store-Operated Channels (SOCs) ROCs}

ROCs are switched on via ligand-mediated activation of receptors coupled to the phospholipase C (PLC) that breaks down PIP2 to produce diacylglycerol (DAG) and inositol 1,4,5-trisphosphate (IP3). DAG activates plasma membrane channels from the TRPC (Transient receptor potential canonical) subfamily, leading to a cationic current $\left(\mathrm{Na}^{+}\right.$and $\left.\mathrm{Ca}^{2+}\right)$, a 
process referred to as receptor-operated $\mathrm{Ca}^{2+}$ entry (ROCE; Vazquez et al., 2001; Dietrich et al., 2005). Because DAG is a second messenger, this channel type can be also called Secondary Messenger-Operated Channels (SMOCs). Among the seven TRPC identified, homotetrameric TRPC3, TRPC6 or TRPC7 channels and heterotetrameric TRPC1-TRPC3 and TRPC3-TRPC4 channels can open in response to DAG application, resulting in $\mathrm{Ca}^{2+}$ influx (Hofmann et al., 1999; Lintschinger et al., 2000; Liu et al., 2005a; Poteser et al., 2006). In contrast, homomeric TRPC1, -4 , and -5 , which are also activated by receptor-induced PLC, are completely unresponsive to DAG (Hofmann et al., 1999; Venkatachalam et al., 2003).

\section{SOCs}

Also known as capacitive $\mathrm{Ca}^{2+}$ entry, store-operated $\mathrm{Ca}^{2+}$ entry (SOCE) represents a widespread type of $\mathrm{Ca}^{2+}$ entry that is triggered upon IP3-dependent depletion of $\mathrm{ER} \mathrm{Ca}^{2+}$ stores (Parekh and Putney, 2005). The ER transmembrane protein Stromal Interaction Molecule 1 (STIM1) senses $\mathrm{Ca}^{2+}$ decrease in the ER and opens SOCs to replenish intracellular $\mathrm{Ca}^{2+}$ stores through SERCA (Sarco/endoplasmic reticulum $\mathrm{Ca}^{2+}$-ATPase) and elicit cellular responses (Parekh and Putney, 2005). Initially identified as CRAC $\left(\mathrm{Ca}^{2+}\right.$ Release-Activated Channels) in $\mathrm{T}$ cells, Orail homopolymers form the core component of SOCs. Although Orail is the ubiquitous SOC protein, Orai2 and Orai3 mediate SOCE in certain specific tissues (Motiani et al., 2010; Wang et al., 2017c). Depending on the cell type and on the STIM1/TRPC channel ratio (Lee et al., 2010), SOCE and ISOCE (the current produced by SOCE) can also be supported by TRPC tetrameric channels (Lopez et al., 2020), which can be formed of TRPC1 and TRPC4 (Sabourin et al., 2009, 2012; Antigny et al., 2017), that interact directly with STIM1 (Huang et al., 2006; Yuan et al., 2007). SOCE and cationic ISOCE can also be the result of functional cooperation between TRPC1 with Orail (Huang et al., 2006; Jardin et al., 2008; Desai et al., 2015; Shin et al., 2016; Ambudkar et al., 2017). SOCE has been recognized as an essential mechanism for $\mathrm{Ca}^{2+}$ uptake in non-excitable cells that, in addition to restoring $\mathrm{ER} \mathrm{Ca}^{2+}$ stores, elicits $\mathrm{Ca}^{2+}$-dependent intracellular signaling cascades involved in cell proliferation, migration, and differentiation.

Further, Orai3 can form a heteromultimeric channel with Orail to build-up arachidonic acid-regulated $\mathrm{Ca}^{2+}$ channels (ARC) or arachidonic acid metabolite Leukotriene C4 (LTC4)regulated $\mathrm{Ca}^{2+}$ channels (LRC; Shuttleworth, 2009; GonzálezCobos et al., 2013). Different works suggest that Orai3 regulates breast, prostate, lung, and gastrointestinal cancers by either forming SOC or ARC/LRC channels in the cancerous cells but not in healthy tissue (Tanwar et al., 2020). Additionally, a recent study reinforces the idea that native CRAC channel is formed by heteromultimerization of Orai1 with Orai2 and/or Orai3, in which Orai2 and Orai3 may act as Orai1 negative regulators (Yoast et al., 2020). Their role would be therefore critical to adapt $\mathrm{Ca}^{2+}$ signals to agonist strengths as proposed for Orai2 in T cells (Vaeth et al., 2017).

\section{Ligand-Gated Ion Channels (LGICs)}

LGICs also commonly referred to as ionotropic receptors, are ion channels whose gating is ligand-dependent. Neurotransmitters serve as ligands for ionotropic receptors. LGICs are opened, or gated, by the binding of a neurotransmitter that triggers a conformational change and results in the conducting state. The LGICs comprise the excitatory, cation-selective, nicotinic acetylcholine- (nAchR; Millar and Gotti, 2009), 5- $\mathrm{HT}_{3}$ serotonin(Barnes et al., 2009), ionotropic glutamate- (Lodge, 2009), the inhibitory, anion-selective, $\mathrm{GABA}_{\mathrm{A}}$ - (Olsen and Sieghart, 2008) and glycine receptors (Lynch, 2009) as well as P2X receptors (Jarvis and Khakh, 2009) gated by extracellular adenosine $5^{\prime}$ triphosphate (ATP; North, 2016). In the central nervous system, activation of $\mathrm{P} 2 \mathrm{X}$ receptors supports $\mathrm{Ca}^{2+}$ entry into neurons and modulates neuron responses. It is also well known that extracellular ATP is abundant in the tumor microenvironment, and since ATP may be leaked by damaged cells, stimulation of P2X channels may be prevalent upon traumatic or ischemic injury (Puchaowicz et al., 2014).

\section{TRPV (Transient Receptor Potential Vanilloid) Channels}

TRPVs are $\mathrm{Ca}^{2+}$ permeable channels of the TRP family (Pedersen and Nilius, 2007) that respond to various signals from the microenvironment such as exogenous chemical ligands, noxious heat, or mechanical stretch. Because of these properties, various channels of the TRPV family, that contains six mammalian members, are known to be involved in nociception (Patapoutian et al., 2009), taste perception (Nilius and Appendino, 2013), thermosensation (Tominaga, 2007) or mechano and osmolarity sensing (Guilak et al., 2010). While heat-activated TRPV1TRPV4 channels that also function as chemosensors are nonselective for cations and modestly permeable to $\mathrm{Ca}^{2+}$, TRPV5 and TRPV6 are highly $\mathrm{Ca}^{2+}$ selective channels with low-temperature sensitivity. Among TRPV channels, TRPV2 is a growth factor-regulated cation channel that was shown to be up-regulated in some cancer cell types, suggesting an oncogenic role, while down-regulated in other tumor cells, suggesting an opposite tumor suppression role (Liberati et al., 2014).

\section{Intracellular $\mathrm{Ca}^{2+}$ Handling and $\mathrm{Ca}^{2+}$ Signaling Pathways}

$\mathrm{Ca}^{2+}$ handling by intracellular reservoirs and transporters may also impact cellular activity. The major $\mathrm{Ca}^{2+}$ store is the ER that releases $\mathrm{Ca}^{2+}$ to the cytoplasm, through two related $\mathrm{Ca}^{2+}$ release channels, namely the ryanodine receptors (RYRs) and inositol 1,4,5-trisphosphate receptors (IP3Rs) in response to multiple factors that include free $\mathrm{Ca}^{2+}$ ion. Three different isoforms of RYRs (RYR1, RYR2, RYR3), each encoded by a different gene, have been identified (Santulli et al., 2018). More widely expressed in most non-excitable cells than RYRs, IP3Rs, displaying three IP3R subtypes, are activated by IP3 produced in response to receptors in the plasma membrane that stimulate phospholipase C (PLC; Mikoshiba, 2015; Berridge, 2016). Specifically, the cell-surface receptors responsible for IP3 formation belong to two main classes, the G protein-coupled receptors (GPCRs) protein and the receptor tyrosine kinases (RTKs) that are coupled to different PLC isoforms (the PLC $\beta$ and PLC$\gamma$ isoforms respectively). During the transduction process, the precursor lipid PIP2 is hydrolyzed by PLC to produce 
both IP3 and DAG. The IP3 released from the membrane diffuses into the cytosol where it binds the IP3Rs, which open and releases $\mathrm{Ca}^{2+}$ from the ER. The subsequent $\mathrm{Ca}^{2+}$ release through IP3Rs as well as the propagation of the $\mathrm{Ca}^{2+}$ signal occurs in a wide range of cells. The $\mathrm{Ca}^{2+}$-mobilizing function of IP3 is terminated through the metabolization of IP3.

$\mathrm{Ca}^{2+}$ entry and/or $\mathrm{Ca}^{2+}$ release through the various channels leads to an increase of cytosolic free $\mathrm{Ca}^{2+}$ concentration whose spatio-temporal pattern and magnitude differentially activate specific signaling pathways (Samanta and Parekh, 2017). These latter rely on various $\mathrm{CaBP}$ of the cytosol, such as calmodulin, calcineurin, PKC, S100 proteins, parvalbumin (Yáñez et al., 2012). While some of them, like parvalbumin or S100, buffer free $\mathrm{Ca}^{2+}$, most of $\mathrm{CaBP}$ decode the $\mathrm{Ca}^{2+}$ signal by selectively turning on specific intracellular signaling cascades (Schwaller, 2010; Yáñez et al., 2012). For instance, the $\mathrm{Ca}^{2+}$ sensor calmodulin modifies its interaction with many effectors upon binding to $\mathrm{Ca}^{2+}$, that in turn, trigger distinct signaling pathways such as mitogen-activated protein kinase/extracellular signalregulated kinase (MEK/ERK), Nuclear factor of activated Tcells (NFAT) or $\mathrm{Ca}^{2+} /$ calmodulin-dependent protein kinase (CAMK) pathways (Hogan et al., 2003). A characteristic feature of the IP3 signaling pathway is that it usually generates a brief transient $\mathrm{Ca}^{2+}$ release that can be repeated to give oscillations over a longer period (Berridge, 1990; Fewtrell, 1993). Many functions, such as gland secretion or differential gene transcription, are controlled by frequency coding of $\mathrm{Ca}^{2+}$ oscillations that, in turn, differentially regulate CaBPs. For instance, the transcription factor nuclear factor kappa B
(NFKB) was shown to be preferentially activated by low frequency repeated $\mathrm{Ca}^{2+}$ transients, whereas NFAT activation needs higher frequencies and a long duration $\mathrm{Ca}^{2+}$ signals (Dolmetsch et al., 1998). The activity of the CAMK II was also reported to be dependent on the frequency of $\mathrm{Ca}^{2+}$ oscillations (De Koninck and Schulman, 1998).

\section{PHYSIOLOGICAL ROLES OF $\mathrm{Ca}^{2+}$ IN NSCs AND THEIR PROGENIES}

NSCs are subjected to a wide range of extracellular cues, each of which contributes to regulate NSC activity. Analysis of the transcriptome of purified adult NSCs highlighted the importance of $\mathrm{Ca}^{2+}$-dependent signaling pathways in these cells (Beckervordersandforth et al., 2010). In parallel, $\mathrm{Ca}^{2+}$ imaging experiments unveiled the existence in NSCs, of intercellular $\mathrm{Ca}^{2+}$ waves that are propagated through gap junctions and that are used by NSCs to communicate with each other and with neighboring niche astrocytes both under physiological conditions (Lacar et al., 2011) and pathological conditions (Kraft et al., 2017). Live cell $\mathrm{Ca}^{2+}$ imaging has also allowed to observe spontaneous $\mathrm{Ca}^{2+}$ oscillations in NSC/progenitors from the V-SVZ (Domenichini et al., 2018) as well as spontaneous high-frequency transients in migrating neuroblasts (Maslyukov et al., 2018). Along with the prominence of transcripts related to the $\mathrm{Ca}^{2+}$ pathway in NSCs, these data lend support to the essential role of $\mathrm{Ca}^{2+}$ in NSCs and their progeny. In the subsequent sections, we will review and discuss the involvement of the $\mathrm{Ca}^{2+}$ toolkit in NSC physiology by analyzing first the implication of plasma membrane channels and then, the function

TABLE 1 | Effects of the $\mathrm{Ca}^{2+}$ toolkit components on neural stem cells (NSCs) and Glioblastoma stem cells (GSCs).

\begin{tabular}{ll}
\hline & Neural stem cells \\
\hline VGCC & Maintain quiescence (T-type, L-type) induced by GABA? ${ }^{(1,2)}$ \\
SOC & Increase proliferation and self-renewal (TRPC1, Orai1) ${ }^{(3,4)}$ \\
TRPV & Decrease proliferation and increase neuronal differentiation (TRPV1) \\
& \\
LGIC & Nicotinic receptors: decrease proliferation and increase neuronal \\
& differentiation ${ }^{(6,7)}$ \\
& NMDA receptors : increase oligodendroglial differentiation, increase \\
& neuroblast survival ${ }^{(8,9)}$ \\
& AMPA receptors : increase neuroblast proliferation ${ }^{(10)}$ \\
& Kainate receptors : decrease neuroblast migration ${ }^{(11)}$ \\
& 5 HT3: increase neuroblast migration ${ }^{(12)}$ \\
& P2X7 receptors: decrease transient amplifying progenitor (C cell) \\
& proliferation ${ }^{(13)}$
\end{tabular}

\author{
Glioblastoma stem cells \\ Increase stemness and survival (T-type) ${ }^{(18,19)}$ \\ Increase proliferation (20) \\ Increase cell death (TRPV1) (21) \\ Decrease stemness (TRPV2) (22) \\ AMPA receptors: increase proliferation and invasion $(24,25)$ \\ P2X7 receptors: decrease proliferation (26) \\ Increase quiescence ${ }^{(27)}$ \\ NFAT1 : increase self-renewal and stemness (28) \\ NFAT2 : increase clonogenicity ${ }^{(29)}$ \\ S100A4 : increase self-renewal (30)
}

Nicotinic receptors: increase stemness and clonogenicity (23)

IP3R Increase self-renewal ${ }^{(14)}$

CaBP NFAT: Increase proliferation (16)

S100B : decrease stemness ${ }^{(17)}$

The table summarizes the major effects reported for $\mathrm{Ca}^{2+}$ toolkit actors in NSCs and their progenies and in GSCs according to the following references: 1. Young et al. (2010); 2. Daynac et al. (2013); 3. Somasundaram et al. (2014); 4. Domenichini et al. (2018); 5. Stock et al. (2014); 6. Narla et al. (2013); 7. Wang et al. (2017b); 8. Cavaliere et al. (2012); 9. Platel et al. (2010); 10. Song et al. (2017); 11. Platel et al. (2008); 12. García-González et al. (2017); 13. Leeson et al. (2018); 14. Kraft et al. (2017); 15. Shi et al. (2005); 16. Serrano-Pérez et al. (2015); 17. Raponi et al. (2007); 18. Niklasson et al. (2017); 19. Zhang et al. (2017); 20. Aulestia et al. (2018), 21. Stock et al. (2014); 22. Morelli et al. (2012); 23. Spina et al. (2016); 24. Venkataramani et al. (2019); 25. Venkatesh et al. (2019); 26. D’Alimonte et al. (2015); 27. Zeniou et al. (2015); 28. Jiang et al. (2019); 29. Song et al. (2020); 30. Chow et al. (2017). 
of intracellular $\mathrm{Ca}^{2+}$ handling and signaling pathways. An overview of the $\mathrm{Ca}^{2+}$ proteins expressed in NSCs and their functions are summarized in Table 1 and in Figures 2D, 4.

\section{Plasma Membrane Channels Voltage-Gated Calcium Channels (VGCCs)}

Both the L-type $\mathrm{Ca}_{V} 1.2$ and the T-type Cav3.1 channels have been detected by RT-PCR in V-SVZ cell cultures that are formed of NSCs and their progenies (Kong et al., 2008). Subsequent analysis of prospectively purified NSCs by flow cytometry disclosed that quiescent NSCs display high expression levels of ion channels among which T- and L-type voltage-gated channels (Khatri et al., 2014). Indeed, electrophysiological recordings combined with pharmacology identified in NSCs (B cells), L- and T-type currents that could be physiologically evoked by GABA (Young et al., 2010). Constitutively present in the germinal niche, GABA that is produced by neuroblasts, tonically activates $\mathrm{GABA}_{\mathrm{A}}$ receptors expressed by NSCs to maintain a quiescent state (Liu et al., 2005b; Daynac et al., 2013; Khatri et al., 2014). $\mathrm{GABA}_{\mathrm{A}}$ receptors are ionotropic receptors that upon interaction with their neurotransmitter activate a depolarizing chloride current in NSCs whose resting membrane potential is close to $-80 \mathrm{mV}$. It was shown that the depolarization elicited by GABA opens VGCCs, which provokes a $\mathrm{Ca}^{2+}$ flux, and that this $\mathrm{Ca}^{2+}$ inflow can be suppressed by the L-Type channel blocker nifedipine or the T-type inhibitor mibefradil (Young et al., 2010). Thus, $\mathrm{Ca}_{\mathrm{V}}$ channels whose expression is enriched in quiescent NSCs (Khatri et al., 2014) could be key players in preventing NSC activation and in preserving their quiescent state in response to the ambient GABA of the V-SVZ. Although this hypothesis requires formal demonstration, the above data suggest that $\mathrm{Ca}_{V}$, by acting on NSC quiescence, would prevent excessive activation of NSCs and avoid NSC exhaustion.

In addition to NSCs, neuroblasts within the olfactory bulb also have been found to possess L-type channels that induce $\mathrm{Ca}^{2+}$ transients whose functions are yet undefined (Darcy and Isaacson, 2009).

\section{Store-Operated Channels (SOCs)}

In the V-SVZ, both Orail and TRPC1 have been detected along with STIM1 in NSCs and also in some neuroblasts (SkibinskaKijek et al., 2009; Somasundaram et al., 2014; Domenichini et al., 2018). In these cells, SOCE could be triggered by various extracellular signals such as EGF that are used for cultures of NSCs (Reynolds et al., 1992; Somasundaram et al., 2014) or SDF1 that controls the tumor tropism of NSCs to glioblastoma (Zhao et al., 2008; Somasundaram et al., 2014). The cholinergic agonist muscarine that stimulates NSC self-renewal could also elicit an intracellular $\mathrm{Ca}^{2+}$ spike followed by a plateau phase that was dependent on SOCE (Domenichini et al., 2018). Conversely, SOCE was significantly but not totally reduced following the Orail knock-out (Somasundaram et al., 2014), indicating that Orail and other actors, possibly TRPC1, build-up functional SOCs in mouse NSCs. The pharmacological blockade of SOC or genetic deletion of Orail resulted in decreased cell proliferation in the V-SVZ without affecting cell death (Somasundaram et al., 2014; Domenichini et al., 2018). Importantly, recruitment of SOC by glutamate or muscarine (Giorgi-Gerevini et al., 2005; Domenichini et al., 2018) promoted NSC self-renewal while SOCE inhibition shifted the mode of NSC division from symmetric proliferative to asymmetric, suggesting that SOCs are required to maintain or expand the pool of NSCs (Domenichini et al., 2018). How SOCs control the mode of cell division is yet unknown and could rely on the ability of SOCE to mobilize specific $\mathrm{Ca}^{2+}$ actors or depend on the capacity of STIM and Orai to localize at the cleavage furrow (Chan et al., 2016).

The importance of SOCs in NSCs is further underscored by a recent study showing that SOCE is required for the transduction of mechanical information due to cerebrospinal fluid flow (Petrik et al., 2018). Specifically, the authors of that study reported that the epithelium sodium channel $(\mathrm{ENaC})$ that is located in the primary cilium of NSCs acts as a mechanosensor and requires a subsequent SOCE to control cell proliferation in V-SVZ in response to cerebrospinal fluid flow (Petrik et al., 2018). Altogether, these data highlight that SOCs play a pivotal role in linking NSC activity to extracellular cues. Of interest, it has been shown in neurons, that after store depletion, STIM1 suppresses the activity of $\mathrm{Ca}_{V} 1.2$ and $\mathrm{Ca}_{V} 3.1$ VGCCs, both of which are expressed in quiescent NSCs and may contribute to maintaining a quiescent state (Harraz and Altier, 2014). Furthermore, it has been shown in muscle cells that SOC and $\mathrm{Ca}_{V}$ can be found in complexes, which would facilitate the switch for recruitment of either SOC or Cav (Ávila-Medina et al., 2016). If STIM1 holds a similar function in NSCs, this observation raises the assumption that STIM1 may orchestrate the shuttling between activity and quiescence of NSCs, by acting both on SOCs to trigger self-renewal and $\mathrm{Ca}_{V}$ channels to release NSCs from the quiescent state constitutively induced by ambient GABA.

\section{Ligand-Gated Ion Channels (LGICs)}

Because NSC activities are tightly controlled by neurotransmitters, several $\mathrm{Ca}^{2+}$-coupled LGICs have been identified as NSC regulators. For instance, NSCs possess, in addition to cholinergic muscarinic receptors that yield transient $\mathrm{Ca}^{2+}$ signals partly through SOCs (Somasundaram et al., 2014; Domenichini et al., 2018), ionotropic nAChRs of the $\alpha 3$ and $\alpha 4$ subtype (Paez-Gonzalez et al., 2014). Also, several studies indicate that other nAChR, namely $\alpha 7$ receptors are also expressed in V-SVZ and that neuroblasts, as well as possibly transient amplifying progenitors, display nAChR (Narla et al., 2013; Sharma, 2013). These receptors are physiologically exposed to acetylcholine in the V-SVZ niche that comes from innervation by cholinergic fibers from the basal forebrain (Calzà et al., 2003; Cooper-Kuhn et al., 2004) and that is also released by a small population of cholinergic neurons residing within the rodent V-SVZ (Paez-Gonzalez et al., 2014). Activation of the local cholinergic neurons or acute infusion of nicotine significantly promoted neurogenesis in vivo (Mudò et al., 2007; Paez-Gonzalez et al., 2014). Conversely, the destruction of basal forebrain cholinergic neurons impeded the production of new neurons (Calzà et al., 2003; Cooper-Kuhn et al., 2004), indicating that ligand-gated cholinergic receptors favor neurogenesis. The use of selective pharmacological and genetic tools identified that 
$\alpha 7$ nicotinic receptors while promoting neuronal differentiation, inhibit proliferation of V-SVZ cells under both physiological conditions or in response to ischemia whereas the $\beta 2$-nAChR subunit control cell survival of newborn neurons (Narla et al., 2013; Wang et al., 2017a,b). Collectively, these studies lend support to a regulatory role of nicotinic receptors in the neurogenic activity of the healthy and diseased brain, albeit the pharmacology of these effects would merit further investigation.

NSCs and neuroblasts also express ionotropic glutamate receptors of the N-methyl-D-aspartate (NMDA), a-amino-3hydroxy-5-méthylisoazol-4-propionate (AMPA), and kainate subtypes (Platel et al., 2008, 2010; Khatri et al., 2014). Although little is known about the functional roles of glutamate receptors in NSCs, kainate and AMPA receptors that trigger $\mathrm{Ca}^{2+}$ influx have been found in neuroblasts where they, respectively, reduce the speed of the migration along the LV (Platel et al., 2008) or boost proliferation as well as promote the ability of these cells to improve brain repair following stroke (Song et al., 2017). In contrast, NMDA receptors seem critical for neuroblast survival during their journey in the RMS before entering the olfactory bulb synaptic network (Platel et al., 2010). Physiologically, the glutamate supply that activates the migrating neuroblasts is secreted by astrocytes, suggesting that astrocytes use glutamate signaling to control the number of adult-born neurons reaching their final destination (Platel et al., 2010). NMDA receptors have also been shown to stimulate oligodendrocyte differentiation in V-SVZ stem/progenitor cells (Cavaliere et al., 2012). Furthermore, AMPA receptors have been detected in oligodendroglial progenitors derived from the $\mathrm{V}-\mathrm{SVZ}$ during the regeneration process occurring after the demyelination of the corpus callosum (Etxeberria et al., 2010). Collectively, these data indicate that glutamate, through the activation of specific subsets of ligand-gated receptors, controls multiple steps of neurogenesis and gliogenesis in the adult brain.

The V-SVZ also harbors serotoninergic receptors that support large rhythmic $\mathrm{Ca}^{2+}$ oscillations in neuroblasts (García-González et al., 2017). Knock-out of the 5HT3A receptor severely reduced $\mathrm{Ca}^{2+}$ spikes, indicating that $5 \mathrm{HT} 3 \mathrm{~A}$ receptors represent a major gate for $\mathrm{Ca}^{2+}$ entry in migrating neuroblasts. Indeed, the speed of migration of neuroblasts was enhanced following optogenetic activation of serotoninergic fibers while it was disrupted by loss-of-function mutation of 5HT3A receptors (García-González et al., 2017), implying that serotoninergic innervation arising from the raphe nuclei governs neuroblast migration through $\mathrm{Ca}^{2+}$ inflow mediated by ionotropic $5 \mathrm{HT} 3 \mathrm{~A}$ receptors (García-González et al., 2017).

In addition to neurotransmitters, V-SVZ cells mobilize $\mathrm{Ca}^{2+}$ in response to extracellular nucleotides whose concentrations increase following brain injury because of their leakage by damaged cells. In addition to their roles in pathological states, nucleotides may also control constitutively the neurogenic niche where high levels of NTDPase2, the enzyme that hydrolyzes nucleotides, have been detected (Braun et al., 2003). Knock-out of NTDPase2 resulted in increased numbers of intermediate progenitors in the $\mathrm{V}-\mathrm{SVZ}$, suggesting that increased levels of extracellular nucleotides favor proliferation in the V-SVZ (Braun et al., 2003). Extracellular nucleotides mediate their effects through metabotropic G-protein-coupled P2Y purinergic receptors and ionotropic purinergic $\mathrm{P} 2 \mathrm{X}$ receptors, both of which are expressed in the V-SVZ and induce $\mathrm{Ca}^{2+}$ transients (Stafford et al., 2007; Messemer et al., 2013). Specifically, the P2X7R subtype that has been detected in ependymal (E) is also expressed in transient amplifying progenitors ( $\mathrm{C}$ cells) where it plays a dual role: in the absence of the ligand, P2X7R functions as a scavenger receptor involved in phagocytosis and following its activation by ATP, the P2X7R reduces proliferation of C cells (Genzen et al., 2009; Messemer et al., 2013; Leeson et al., 2018). It should be mentioned here that although these data appear contradictory with the fact that increased levels of extracellular nucleotides favor cell proliferation, ATP also acts on other receptors among which the metabotropic P2Y1R receptors that foster expansion of the C cell population (Suyama et al., 2012). The multiplicity of receptors targeted by extracellular nucleotides shapes a unique and selective response to these ligands.

\section{TRPV (Transient Receptor Potential Vanilloid) Channels}

Among the TRPV channels, TRPV1 has been detected within the V-SVZ in $20 \%$ of NSCs, in transient amplifying progenitors and in neuroblasts during the early postnatal period (Stock et al., 2014). TRPV1 expression then declines in 1 month old mice along with the diminution of neurogenesis, although radioautography figures published by Roberts et al. (2004) show some binding sites of TRPV1 in the V-SVZ of adult mice brain stained with radiolabeled TRPV1 ligands (Roberts et al., 2004; Stock et al., 2014). Interestingly, TRPV1 expression could be up-regulated in adulthood by physiological situations known to promote neurogenesis (Stock et al., 2014). In mice, deletion of TRPV1 conducted to a substantial rise in proliferating cells, but lesser differentiation to neurons or glia in the neurogenic niches of the postnatal brain. Thus, the loss of TRPV1 in neural stem/progenitor cells disturbs differentiation and the growth potential of V-SVZ stem cells, suggesting that TRPV1 coordinates the coupling between proliferation and differentiation of neural precursors (Stock et al., 2014).

\section{Intracellular $\mathrm{Ca}^{2+}$ Handling and $\mathrm{Ca}^{2+}$ Signaling Pathways}

Several studies have underlined that maintenance of NSCs and of their activity requires an appropriate handling of the ER $\mathrm{Ca}^{2+}$ reservoir. For instance, the $\mathrm{Ca}^{2+}$ waves that promote NSC self-renewal following injury are IP3-dependent (Kraft et al., 2017). Conversely, activation of the $\mathrm{Ca}^{2+}$ efflux from the ER by the pro-apoptotic protein Bax increased cell death, which was substantially hampered by siRNA-mediated suppression of IP3R expression (Shi et al., 2005). These data underscore the necessity of a strict handling of $\mathrm{Ca}^{2+}$ for keeping the NSC population.

CaBP also play essential roles in modulation of NSC activity. Among these, NFAT, especially the NFATc1 and NFATc3 isoforms, is expressed in newborn rodent V-SVZ cell cultures (Serrano-Pérez et al., 2015). Interestingly, the recruitment of NFAT occurred only in response to local $\mathrm{Ca}^{2+}$ signals obtained following SOC activation but not global $\mathrm{Ca}^{2+}$ transients, illustrating that specific $\mathrm{Ca}^{2+}$ patterns are required 
for selective responses (Somasundaram et al., 2014). Analysis of NFAT function showed that the NFAT inhibitor VIVIT slowed cell cycle in NSCs and reduced their ability to differentiate (Serrano-Pérez et al., 2015). Yet, a possible involvement of NFAT for keeping a multipotential stem cell state, that has been observed in embryonic stem cells (MacDougall et al., 2019), remains to be investigated. Noteworthy, $\mathrm{Ca}^{2+}$ buffering proteins may also control stemness as it has been shown that S100B expression is associated with a loss of NSC potential of GFAP-expressing cells (Raponi et al., 2007).

In addition, a wide transcriptomic study in migrating neuroblasts isolated from the RMS identified the calmodulin signaling network as one of the four up-regulated networks in these cells (Khodosevich et al., 2009). Silencing in vivo the expression of specific genes of this network, namely calmodulin (calm1) and CamKinase (CamK4), conducted to a decrease in the numbers of neuroblasts that reached the olfactory bulb, indicating that calmodulin and its effector are essential players for neuroblast migration (Khodosevich et al., 2009).

\section{PHYSIOPATHOLOGICAL ROLES OF $\mathrm{Ca}^{2+}$ IN GSCs}

Alterations in the $\mathrm{Ca}^{2+}$ toolkit have been reported in human tissues resected from glioblastoma, with increased expressions of TRPC (C1, C6) and TRPV (V1, V2) channels as compared to normal tissue (Alptekin et al., 2015). Transcriptomic analysis of GSCs unveiled that $\mathrm{Ca}^{2+}$ channels and signaling pathways, that elicit vital cell functions in response to extracellular cues, are enriched in GSCs, as compared to more mature non-stem glioblastoma cells that express more $\mathrm{Ca}^{2+}$ buffers (Wee et al., 2014). Such alterations most likely lead to modified $\mathrm{Ca}^{2+}$ homeostasis and $\mathrm{Ca}^{2+}$ codes that subsequently, may trigger tumorigenic behavior. In accordance, the epigenetic drugs that increase stemness of GSCs modify the $\mathrm{Ca}^{2+}$ signaling pathway (Wang et al., 2018). Interestingly, a screen of a chemical library of 72 ion channel blockers identified that 10 drugs among the 12 drugs capable of reducing GSC viability act on $\mathrm{Ca}^{2+}$-related signaling networks, supporting that $\mathrm{Ca}^{2+}$ channels or transporters may be appealing targets in GSCs (Niklasson et al., 2017).

In the following sections, we will examine the involvement of the $\mathrm{Ca}^{2+}$ toolkit in GSCs by reviewing first the implication of plasma membrane channels and then, the function of intracellular $\mathrm{Ca}^{2+}$ handling and signaling pathways. An overview of the $\mathrm{Ca}^{2+}$ proteins expressed and their functions in GSCs is provided in Figure 4 and summarized in Table 1.

\section{Plasma Membrane Channels Voltage-Gated Calcium Channels (VGCCs)}

T-type voltage-gated $\mathrm{Ca}^{2+}$ channels (Cav 3.2) whose overexpression has been associated with a worse prognosis, have been found enriched in GSCs of glioblastoma as compared to either non-GSC-tumor cells or normal tissue (Wee et al., 2014; Zhang et al., 2017). Hypoxia, known to promote resistance to anticancer therapies, increased expression of the $\mathrm{Ca}_{\mathrm{V}} 3.2$ VGCC in GSCs. Conversely, treatment with mibefradil, a FDA-approved inhibitor of $\mathrm{Ca}_{\mathrm{V}} 3.2$ that is used to treat hypertension, substantially reduced the GSC population by promoting their differentiation and reducing their viability (Niklasson et al., 2017; Zhang et al., 2017). This effect was mimicked by RNAi-mediated attenuation of Cav3.2 expression (Zhang et al., 2017). Because resistance to treatments represents a major hurdle in current oncology, the fact that oral administration of mibefradil in mice xenografted with GSCs sensitized them to temozolomide treatment and prolonged survival of mice, opens new perspectives to improve the therapies against glioblastoma (Zhang et al., 2017). Among the mechanisms that may underpin these effects, it has been proposed that T-Type blockers compromise GSC survival by blocking the $\mathrm{Ca}^{2+}$ influx required to recruit $\mathrm{Ca}^{2+}$-dependent $\mathrm{K}^{+}$ channels (KCa) whose activity is mandatory for the maintenance of cell polarity. This induces cell depolarization, thereby precluding the $\mathrm{Na}^{+}$-dependent transport of nutrients and ultimately leading to starvation (Niklasson et al., 2017).

\section{Store-Operated Channels (SOCs)}

SOCE is a ubiquitous $\mathrm{Ca}^{2+}$ influx that occurs in a wide range of cells, in response to numerous extracellular signals. During a characterization of the set of genes involved in $\mathrm{Ca}^{2+}$ signal generation differentially expressed in brain tumors and normal tissue, genes related to SOCE were found to be strongly perturbed, and one of the major actors of SOC, Orai 1, was disclosed as one of the genes whose expression is up-regulated in glioblastoma tissues and in GSCs (Robil et al., 2015). Already involved in promoting invasion capacities of glioblastoma cells (Motiani et al., 2013), Orail and/or SOC that are highly expressed in GSCs, could preserve or expand the population of GSCs. Indeed, inhibition of SOC channels with SKF-96365 reduced cell proliferation of GSCs and induced a quiescent transcriptomic signature in these cells (Aulestia et al., 2018). Altogether, these data suggest that SOCs may be pivotal for glioblastoma initiation, expansion, infiltration of the normal tissue and tumor relapse.

\section{Ligand-Gated Ion Channels (LGICs)}

As for NSCs, AMPA receptors have been detected at high concentrations in GSCs, as compared to the differentiated non-stem tumor cells (Oh et al., 2012; Wee et al., 2014). Two elegant studies recently established that AMPA receptors expressed by human glioma cells, cultured in stem cell conditions, mediate tumor cell interactions with surrounding neurons through authentic neuron-glioma glutamatergic synapses. It was shown that neuronal activity-mediated release of glutamate drives glioma progression by promoting glioma growth and invasion through $\mathrm{Ca}^{2+}$-dependent mechanisms involving AMPA receptors (Venkataramani et al., 2019; Venkatesh et al., 2019).

A screen of chemical libraries identified the nicotinic receptor antagonist, atracurium besylate, as a small molecule that effectively inhibits the clonogenic capacity and induces astroglial differentiation of patient-derived GSCs. Conversely, a nicotinic receptor agonist prevented atracurium besylate ability to reduce GSC self-renewal. Furthermore, this study showed that the survival of mice xenotransplanted with GSCs pretreated with atracurium besylate was significantly improved, suggesting that 
blockade of nicotinic cholinergic receptors may reduce GSC stemness and/or cell population (Spina et al., 2016).

Extracellular nucleotides found in the microenvironment also contribute to defining GSC activity. Indeed, it has been shown that as compared to more differentiated tumoral cells, GSCs release tenfold more extracellular adenosine (Torres et al., 2019) that may act as autocrine/paracrine ligand to activate G-protein-coupled P2Y1R purinergic receptors or ionotropic purinergic P2X7R receptors to respectively promote or restrain GSC proliferation (D'Alimonte et al., 2015).

\section{TRPV Channels}

Analysis of TRPV1 and TRPV2 expression showed that they are up-regulated in glioblastoma as compared to normal tissue (Alptekin et al., 2015). Studies of their possible functions demonstrated that the vanilloid receptor TRPV1 triggers tumor cell death in glioblastoma cells. Of interest it was shown that endovanilloids (TRPV1 ligands) are secreted by the NSCs that migrate to the tumor mass, and that the oncostatic effect that NSCs exert on the tumor involves the release of endovanilloids (Stock et al., 2014). TRPV2 on the other hand, reduces GSC stemness. Indeed, overexpression of TRPV2 was found to diminish GSC proliferation and promote their differentiation as glial cells both in vitro and in vivo in mice xenografted with TRPV2-overexpressing GSCs (Morelli et al., 2012).

\section{Intracellular $\mathrm{Ca}^{2+}$ Handling and $\mathrm{Ca}^{2+}$ Signaling Pathways}

$\mathrm{Ca}^{2+}$ stores of intracellular organelles, the ER and mitochondria, seem also involved in modulating GSC properties, particularly in the acquisition of a quiescent phenotype, which allows GSCs to escape from current anti-cancer therapies. The involvement of IP3R has been found following the discovery of a selective cytotoxic agent called bisacodyl that was picked out during the screening of the chemical Prestwick library for its power of eradication of quiescent GSCs (Zeniou et al., 2015). Consecutive studies disclosed that this drug acts on IP3R to block $\mathrm{Ca}^{2+}$ efflux from the ER (Dong et al., 2017). Thus, the maintenance of the quiescence in GSCs and resistance to chemotherapies may rely on a specific handling of $\mathrm{Ca}^{2+}$ from the ER. In addition to ER, mitochondrial management of $\mathrm{Ca}^{2+}$ may be involved in the control of GSC stem cell state. In support of this hypothesis, transcriptomic analysis of the $\mathrm{Ca}^{2+}$ toolbox underlined an up-regulated expression of the mitochondrial $\mathrm{Ca}^{2+}$ transporter $\mathrm{MCU}$ and of the $\mathrm{Ca}^{2+} / \mathrm{Na}^{+}$ exchanger SLC8A3 in GSCs (Robil et al., 2015). Subsequently, it was described that proliferating cells have more sustained $\mathrm{Ca}^{2+}$ signals than quiescent GSCs and that these changes in $\mathrm{Ca}^{2+}$ responses are associated with mitochondrial remodeling, suggesting that mitochondrial $\mathrm{Ca}^{2+}$ might control quiescence of GSCs although this hypothesis needs to be experimentally challenged (Aulestia et al., 2018).

CaBP have also been involved in GSC stemness. Specifically, the levels of S100A4 expression have been identified as an independent prognostic indicator of glioma patient survival, the worse prognosis being associated with up-regulated S100A4 expression in patients with glioblastoma of the mesenchymal molecular subgroup (Chow et al., 2017). Further analysis showed that S100A4-expressing cells are enriched with GSCs and are required for GSC self-renewal and survival. Selective ablation of the S100A4-expressing cells in genetically engineered mice that form spontaneous gliomas was sufficient to compromise tumor growth (Chow et al., 2017).

$\mathrm{Ca}^{2+}$-dependent signaling pathways also contribute to GSC stemness or activity. Indeed, a recent study showed that NFAT1 expression is upregulated in GSCs as compared to more differentiated glioma cells. NFAT1 knockdown compromised GSC viability, impaired their self-renewal and migration abilities in vitro, and inhibited tumorigenesis in vivo. Conversely, NFAT1 overexpression promoted glioma growth through a mechanism involving the neurodevelopment protein 1-like 1 (NDEL1) that with NFAT1, controlled the maintenance of a naive stem cell state in GSCs (Jiang et al., 2019). In addition, NFAT2 may also represents a possible regulator of GSCs, especially of the mesenchymal glioblastoma subtype where it drives invasion and clonogenicity and promotes tumor growth through the regulation of HDAC1 (Song et al., 2020).

\section{CONCLUDING REMARKS}

Our review highlights a central role of $\mathrm{Ca}^{2+}$ in both NSCs and GSCs, which is correlated to prominence of $\mathrm{Ca}^{2+}$-related transcripts in both cell types. Indeed, NSCs and GSCs possess, each, a specific $\mathrm{Ca}^{2+}$ toolkit that allows to maintain $\mathrm{Ca}^{2+}$ homeostasis and to encode specific $\mathrm{Ca}^{2+}$ signals in response to the numerous signals from their microenvironment. Several functions of specific $\mathrm{Ca}^{2+}$ components in NSCs and GSCs have been unveiled. Current available data underpins that stemness is controlled by VGCCs, SOCs and IP3Rs in NSCs while it is regulated by VGCCs, nicotinic receptors, TRPVs and NFAT in GSCs, indicating that there might be cell type specific effects of $\mathrm{Ca}^{2+}$ toolkit components. Such differences may rely on either a differential expression of $\mathrm{Ca}^{2+}$ toolkit elements that, in turn, generates differential responses, or on yet unexplored functions of specific $\mathrm{Ca}^{2+}$ components in GSCs and NSCs, or both. It should also be kept in mind that the $\mathrm{Ca}^{2+}$ signals produced in a cell not only depend on $\mathrm{Ca}^{2+}$ release in the cytoplasm but also on its extrusion, a process that influences the spatial and temporal extent of the $\mathrm{Ca}^{2+}$ signal. Concerning the pumps, whose activity shapes the $\mathrm{Ca}^{2+}$ responses, little is known on their expression and functions in either NSCs or GSCs.

In vivo, cells evolve in microenvironments with multiple extracellular cues, many of which elicit $\mathrm{Ca}^{2+}$ signals and control cellular activities. Thus, it will be of importance to understand how the different signals are integrated and conduct to a specific $\mathrm{Ca}^{2+}$ signal within each cell type. Along with this latter question, the downstream effectors recruited by the different $\mathrm{Ca}^{2+}$ signals will require further investigation in order to understand how the specific spatio-temporal and magnitude profiles of $\mathrm{Ca}^{2+}$ signals select a cellular response. Reciprocally, it will be essential to understand the impact of the microenvironment and of pathological states on the remodeling of the $\mathrm{Ca}^{2+}$ toolkit of 
NSCs and GSCs, as it has been observed for endothelial cells (Lodola et al., 2012; Moccia et al., 2020).

An in-depth knowledge of the $\mathrm{Ca}^{2+}$ toolkit in both NSCs and GSCs will contribute to understand the impact of $\mathrm{Ca}^{2+}$ alterations or dysregulation during aging and disease and will help to develop pharmacological strategies to combat brain diseases. Indeed, the remodeling of intracellular $\mathrm{Ca}^{2+}$ homeostasis is considered as a cellular and molecular hallmark of brain aging (Kumar et al., 2009; Gheorghe et al., 2014; Mattson and Arumugam, 2018) and represents one of the earliest abnormalities in both the familial and sporadic forms of Alzheimer's disease (Alzheimer's Association Calcium Hypothesis Workgroup, 2017; Popugaeva et al., 2018). However, age-related changes of the $\mathrm{Ca}^{2+}$ toolkit have not been explored in the V-SVZ so far. Yet, some molecules targeting the $\mathrm{Ca}^{2+}$ toolkit are already being tested in clinical trials for the treatment of glioblastoma. Among them, carboxyamidotriazole that inhibits non-VGCCs and disrupts $\mathrm{Ca}^{2+}$-mediated signal transduction, showed some promising results in a recent multicenter phase IB trial when

\section{REFERENCES}

Ahlenius, H., Visan, V., Kokaia, M., Lindvall, O., and Kokaia, Z. (2009). Neural stem and progenitor cells retain their potential for proliferation and differentiation into functional neurons despite lower number in aged brain. J. Neurosci. 29, 4408-4419. doi: 10.1523/JNEUROSCI.6003-08.2009

Alcantara Llaguno, S., Chen, J., Kwon, C.-H., Jackson, E. L., Li, Y., Burns, D. K., et al. (2009). Malignant astrocytomas originate from neural stem/progenitor cells in a somatic tumor suppressor mouse model. Cancer Cell 15, 45-56. doi: 10.1016/j.ccr.2008.12.006

Alonso, M., Lepousez, G., Sebastien, W., Bardy, C., Gabellec, M.-M., Torquet, N., et al. (2012). Activation of adult-born neurons facilitates learning and memory. Nat. Neurosci. 15, 897-904. doi: 10.1038/nn.3108

Alptekin, M., Eroglu, S., Tutar, E., Sencan, S., Geyik, M. A., Ulasli, M., et al. (2015). Gene expressions of TRP channels in glioblastoma multiforme and relation with survival. Tumour Biol. 36, 9209-9213. doi: 10.1007/s13277-015-3577-x

Altman, J. (1963). Autoradiographic investigation of cell proliferation in the brains of rats and cats. Anat. Rec. 145, 573-591. doi: 10.1002/ar.1091450409

Altman, J. (1969). Autoradiographic and histological studies of postnatal neurogenesis. IV. Cell proliferation and migration in the anterior forebrain, with special reference to persisting neurogenesis in the olfactory bulb. J. Comp. Neurol. 137, 433-457. doi: 10.1002/cne.901370404

Altman, J., and Das, G. D. (1965). Autoradiographic and histological evidence of postnatal hippocampal neurogenesis in rats. J. Comp. Neurol. 124, 319-335. doi: $10.1002 /$ cne. 901240303

Alzheimer's Association Calcium Hypothesis Workgroup. (2017). Calcium Hypothesis of Alzheimer's disease and brain aging: a framework for integrating new evidence into a comprehensive theory of pathogenesis. Alzheimers Dement. 13, 178.e17-182.e17. doi: 10.1016/j.jalz.2016.12.006

Ambudkar, I. S., de Souza, L. B., and Ong, H. L. (2017). TRPC1, Orail, and STIM1 in SOCE: friends in tight spaces. Cell Calcium 63, 33-39. doi: 10.1016/j. ceca.2016.12.009

Antigny, F., Sabourin, J., Saüc, S., Bernheim, L., Koenig, S., and Frieden, M. (2017). TRPC1 and TRPC4 channels functionally interact with STIM1L to promote myogenesis and maintain fast repetitive $\mathrm{Ca}^{2+}$ release in human myotubes. Biochim. Biophys. Acta Mol. Cell Res. 1864, 806-813. doi: 10.1016/j.bbamcr. 2017.02.003

Arvidsson, A., Collin, T., Kirik, D., Kokaia, Z., and Lindvall, O. (2002). Neuronal replacement from endogenous precursors in the adult brain after stroke. Nat. Med. 8, 963-970. doi: 10.1038/nm747

Aulestia, F. J., Néant, I., Dong, J., Haiech, J., Kilhoffer, M.-C., Moreau, M., et al. (2018). Quiescence status of glioblastoma stem-like cells involves used in combination with temozolomide, prompting further deciphering of the roles of $\mathrm{Ca}^{2+}$ channels in GSCs and NSCs (Omuro et al., 2018).

\section{AUTHOR CONTRIBUTIONS}

VC wrote the initial manuscript draft. VC, ET, ND, PA and BC revised and approved the manuscript. All authors contributed to the article and approved the submitted version.

\section{FUNDING}

This work was funded by La Ligue Contre le Cancer Grand Ouest, Comités de la Vienne et des Deux Sèvres.

\section{ACKNOWLEDGMENTS}

We thank La Ligue Contre le Cancer Grand Ouest, Comités de la Vienne et des Deux Sèvres for financial support.

remodelling of $\mathrm{Ca}^{2+}$ signalling and mitochondrial shape. Sci. Rep. 8:9731. doi: 10.1038/s41598-018-28157-8

Ávila-Medina, J., Calderón-Sánchez, E., González-Rodríguez, P., MonjeQuiroga, F., Rosado, J. A., Castellano, A., et al. (2016). Orail and TRPC1 proteins co-localize with CaV1.2 channels to form a signal complex in vascular smooth muscle cells. J. Biol. Chem. 291, 21148-21159. doi: 10.1074/jbc. M116.742171

Bacigaluppi, M., Sferruzza, G., Butti, E., Ottoboni, L., and Martino, G. (2020). Endogenous neural precursor cells in health and disease. Brain Res. 1730:146619. doi: 10.1016/j.brainres.2019.146619

Bao, S., Wu, Q., McLendon, R. E., Hao, Y., Shi, Q., Hjelmeland, A. B., et al. (2006). Glioma stem cells promote radioresistance by preferential activation of the DNA damage response. Nature 444, 756-760. doi: 10.1038/nature05236

Barami, K. (2007). Biology of the subventricular zone in relation to gliomagenesis. J. Clin. Neurosci. 14, 1143-1149. doi: 10.1016/j.jocn.2007.04.009

Barnes, N. M., Hales, T. G., Lummis, S. C. R., and Peters, J. A. (2009). The 5-HT3 receptor-the relationship between structure and function. Neuropharmacology 56, 273-284. doi: 10.1016/j.neuropharm.2008.08.003

Bauer, R., Kaiser, M., and Stoll, E. (2014). A computational model incorporating neural stem cell dynamics reproduces glioma incidence across the lifespan in the human population. PLoS One 9:e111219. doi: 10.1371/journal.pone. 0111219

Bauer, S., Hay, M., Amilhon, B., Jean, A., and Moyse, E. (2005). In vivo neurogenesis in the dorsal vagal complex of the adult rat brainstem. Neuroscience 130, 75-90. doi: 10.1016/j.neuroscience.2004.08.047

Beckervordersandforth, R., and Rolando, C. (2019). Untangling human neurogenesis to understand counteract brain disorders. Curr. Opin. Pharmacol. 50, 67-73. doi: 10.1016/j.coph.2019.12.002

Beckervordersandforth, R., Tripathi, P., Ninkovic, J., Bayam, E., Lepier, A., Stempfhuber, B., et al. (2010). in vivo fate mapping and expression analysis reveals molecular hallmarks of prospectively isolated adult neural stem cells. Cell Stem Cell 7, 744-758. doi: 10.1016/j.stem.2010.11.017

Bédard, A., and Parent, A. (2004). Evidence of newly generated neurons in the human olfactory bulb. Dev. Brain Res. 151, 159-168. doi: 10.1016/j.devbrainres. 2004.03.021

Bergmann, O., Liebl, J., Bernard, S., Alkass, K., Yeung, M. S. Y., Steier, P., et al. (2012). The age of olfactory bulb neurons in humans. Neuron 74, 634-639. doi: 10.1016/j.neuron.2012.03.030

Bernier, P. J., Bédard, A., Vinet, J., Lévesque, M., and Parent, A. (2002) Newly generated neurons in the amygdala and adjoining cortex of adult primates. Proc. Natl. Acad. Sci. U S A 99, 11464-11469. doi: 10.1073/pnas.1724 03999 
Berridge, M. J. (1990). Calcium oscillations. J. Biol. Chem. 265, 9583-9586.

Berridge, M. J. (2016). The inositol trisphosphate/calcium signaling pathway in health and disease. Physiol. Rev. 96, 1261-1296. doi: 10.1152/physrev.00006. 2016

Berridge, M. J., Bootman, M. D., and Roderick, H. L. (2003). Calcium signalling: dynamics, homeostasis and remodelling. Nat. Rev. Mol. Cell Biol. 4, 517-529. doi: $10.1038 / \mathrm{nrm} 1155$

Boldrini, M., Fulmore, C. A., Tartt, A. N., Simeon, L. R., Pavlova, I., Poposka, V., et al. (2018). Human hippocampal neurogenesis persists throughout aging. Cell Stem Cell 22, 589.e5-599.e5. doi: 10.1016/j.stem.2018.03.015

Bouab, M., Paliouras, G. N., Aumont, A., Forest-Bérard, K., and Fernandes, K. J. L. (2011). Aging of the subventricular zone neural stem cell niche: evidence for quiescence-associated changes between early and mid-adulthood. Neuroscience 173, 135-149. doi: 10.1016/j.neuroscience.2010.11.032

Braun, N., Sévigny, J., Mishra, S. K., Robson, S. C., Barth, S. W., Gerstberger, R., et al. (2003). Expression of the ecto-ATPase NTPDase2 in the germinal zones of the developing and adult rat brain. Eur. J. Neurosci. 17, 1355-1364. doi: 10.1046/j.1460-9568.2003.02567.x

Brousse, B., Magalon, K., Durbec, P., and Cayre, M. (2015). Region and dynamic specificities of adult neural stem cells and oligodendrocyte precursors in myelin regeneration in the mouse brain. Biol. Open 4, 980-992. doi: 10.1242/bio. 012773

Butti, E., Bacigaluppi, M., Chaabane, L., Ruffini, F., Brambilla, E., Berera, G., et al. (2019). Neural stem cells of the subventricular zone contribute to neuroprotection of the corpus callosum after cuprizone-induced demyelination. J. Neurosci. 39, 5481-5492. doi: 10.1523/JNEUROSCI. 0227-18.2019

Calzà, L., Giuliani, A., Fernandez, M., Pirondi, S., D’Intino, G., Aloe, L., et al. (2003). Neural stem cells and cholinergic neurons: regulation by immunolesion and treatment with mitogens, retinoic acid and nerve growth factor. Proc. Natl. Acad. Sci. U S A 100, 7325-7330. doi: 10.1016/j.neulet.2020.135403

Capilla-Gonzalez, V., Cebrian-Silla, A., Guerrero-Cazares, H., GarciaVerdugo, J. M., and Quiñones-Hinojosa, A. (2013). The generation of oligodendroglial cells is preserved in the rostral migratory stream during aging. Front. Cell. Neurosci. 7:147. doi: 10.3389/fncel.2013.00147

Capilla-Gonzalez, V., Cebrian-Silla, A., Guerrero-Cazares, H., GarciaVerdugo, J. M., and Quiñones-Hinojosa, A. (2014a). Age-related changes in astrocytic and ependymal cells of the subventricular zone. Glia 62, 790-803. doi: 10.1002/glia.22642

Capilla-Gonzalez, V., Guerrero-Cazares, H., Bonsu, J. M., Gonzalez-Perez, O., Achanta, P., Wong, J., et al. (2014b). The subventricular zone is able to respond to a demyelinating lesion after localized radiation. Stem Cells 32, 59-69. doi: 10.1002/stem.1519

Capilla-Gonzalez, V., Herranz-Pérez, V., and García-Verdugo, J. M. (2015). The aged brain: genesis and fate of residual progenitor cells in the subventricular zone. Front. Cell. Neurosci. 9:365. doi: 10.3389/fncel.2015.00365

Catterall, W. A. (2011). Voltage-gated calcium channels. Cold Spring Harb. Perspect. Biol. 3:a003947. doi: 10.1101/cshperspect.a003947

Catterall, W. A., Perez-Reyes, E., Snutch, T. P., and Striessnig, J. (2005). International union of pharmacology. XLVIII. Nomenclature and structurefunction relationships of voltage-gated calcium channels. Pharmacol. Rev. 57, 411-425. doi: 10.1124/pr.57.4.5

Cavaliere, F., Urra, O., Alberdi, E., and Matute, C. (2012). Oligodendrocyte differentiation from adult multipotent stem cells is modulated by glutamate. Cell Death Dis. 3:e268. doi: 10.1038/cddis.2011.144

Chan, C. M., Aw, J. T. M., Webb, S. E., and Miller, A. L. (2016). SOCE proteins, STIM1 and Orail, are localized to the cleavage furrow during cytokinesis of the first and second cell division cycles in zebrafish embryos. Zygote 24, 880-889. doi: 10.1017/S0967199416000216

Charrier, C., Coronas, V., Fombonne, J., Roger, M., Jean, A., Krantic, S., et al. (2006). Characterization of neural stem cells in the dorsal vagal complex of adult rat by in vivo proliferation labeling and in vitro neurosphere assay. Neuroscience 138, 5-16. doi: 10.1016/j.neuroscience.2005. 10.046

Chen, J., Li, Y., Yu, T.-S., McKay, R. M., Burns, D. K., Kernie, S. G., et al. (2012). A restricted cell population propagates glioblastoma growth following chemotherapy. Nature 488, 522-526. doi: 10.1038/nature 11287
Chesnelong, C., Restall, I., and Weiss, S. (2019). Isolation and culture of glioblastoma brain tumor stem cells. Methods Mol. Biol. 1869, 11-21. doi: 10.1007/978-1-4939-8805-1_2

Chow, K.-H., Park, H. J., George, J., Yamamoto, K., Gallup, A. D., Graber, J. H., et al. (2017). S100A4 is a biomarker and regulator of glioma stem cells that is critical for mesenchymal transition in glioblastoma. Cancer Res. 77, 5360-5373. doi: 10.1158/0008-5472.CAN-17-1294

Cooper-Kuhn, C. M., Winkler, J., and Kuhn, H. G. (2004). Decreased neurogenesis after cholinergic forebrain lesion in the adult rat. J. Neurosci. Res. 77, 155-165. doi: 10.1002/jnr.20116

Curtis, M. A., Kam, M., Nannmark, U., Anderson, M. F., Axell, M. Z., Wikkelso, C., et al. (2007). Human neuroblasts migrate to the olfactory bulb via a lateral ventricular extension. Science 315, 1243-1249. doi: 10.1126/science.1136281

D’Alimonte, I., Nargi, E., Zuccarini, M., Lanuti, P., Di Iorio, P., Giuliani, P., et al. (2015). Potentiation of temozolomide antitumor effect by purine receptor ligands able to restrain the in vitro growth of human glioblastoma stem cells. Purinergic Signal. 11, 331-346. doi: 10.1007/s11302-015-9454-7

Darcy, D. P., and Isaacson, J. S. (2009). L-type calcium channels govern calcium signaling in migrating newborn neurons in the postnatal olfactory bulb. J. Neurosci. 29, 2510-2518. doi: 10.1523/JNEUROSCI.5333-08.2009

Daynac, M., Chicheportiche, A., Pineda, J. R., Gauthier, L. R., Boussin, F. D., and Mouthon, M.-A. (2013). Quiescent neural stem cells exit dormancy upon alteration of GABAAR signaling following radiation damage. Stem Cell Res. 11, 516-528. doi: 10.1016/j.scr.2013.02.008

De Koninck, P., and Schulman, H. (1998). Sensitivity of CaM kinase II to the frequency of $\mathrm{Ca}^{2+}$ oscillations. Science 279, 227-230. doi: 10.1126/science.279. 5348.227

Déliot, N., and Constantin, B. (2015). Plasma membrane calcium channels in cancer: alterations and consequences for cell proliferation and migration. Biochim. Biophys. Acta 1848, 2512-2522. doi: 10.1016/j.bbamem.2015. 06.009

Demars, M., Hu, Y.-S., Gadadhar, A., and Lazarov, O. (2010). Impaired neurogenesis is an early event in the etiology of familial Alzheimer's disease in transgenic mice. J. Neurosci. Res. 88, 2103-2117. doi: 10.1002/jnr. 22387

Desai, P. N., Zhang, X., Wu, S., Janoshazi, A., Bolimuntha, S., Putney, J. W., et al. (2015). Multiple types of calcium channels arising from alternative translation initiation of the Orail message. Sci. Signal. 8:ra74. doi: 10.1126/scisignal. aaa8323

Dietrich, A., Kalwa, H., Rost, B. R., and Gudermann, T. (2005). The diacylgylcerolsensitive TRPC3/6/7 subfamily of cation channels: functional characterization and physiological relevance. Pflugers Arch. 451, 72-80. doi: 10.1007/s00424005-1460-0

Doetsch, F., Caillé, I., Lim, D. A., García-Verdugo, J. M., and Alvarez-Buylla, A. (1999a). Subventricular zone astrocytes are neural stem cells in the adult mammalian brain. Cell 97, 703-716. doi: 10.1016/s0092-8674(00)80783-7

Doetsch, F., García-Verdugo, J. M., and Alvarez-Buylla, A. (1999b). Regeneration of a germinal layer in the adult mammalian brain. Proc. Natl. Acad. Sci. U S A 96, 11619-11624. doi: 10.1073/pnas.96.20.11619

Doetsch, F., García-Verdugo, J. M., and Alvarez-Buylla, A. (1997). Cellular composition and three-dimensional organization of the subventricular germinal zone in the adult mammalian brain. J. Neurosci. 17, 5046-5061. doi: 10.1523/JNEUROSCI.17-13-05046.1997

Dolmetsch, R. E., Xu, K., and Lewis, R. S. (1998). Calcium oscillations increase the efficiency and specificity of gene expression. Nature 392, 933-936. doi: $10.1038 / 31960$

Domenichini, F., Terrié, E., Arnault, P., Harnois, T., Magaud, C., Bois, P., et al. (2018). Store-operated calcium entries control neural stem cell self-renewal in the adult brain subventricular zone. Stem Cells 36, 761-774. doi: 10.1002/ stem.2786

Dong, J., Aulestia, F. J., Assad Kahn, S., Zeniou, M., Dubois, L. G., El-Habr, E. A., et al. (2017). Bisacodyl and its cytotoxic activity on human glioblastoma stem-like cells. Implication of inositol 1,4,5-triphosphate receptor dependent calcium signaling. Biochim. Biophys. Acta Mol. Cell Res. 1864, 1018-1027. doi: 10.1016/j.bbamcr.2017.01.010

Eriksson, P. S., Perfilieva, E., Björk-Eriksson, T., Alborn, A. M., Nordborg, C., Peterson, D. A., et al. (1998). Neurogenesis in the adult human hippocampus. Nat. Med. 4, 1313-1317. doi: 10.1038/3305 
Ernst, A., Alkass, K., Bernard, S., Salehpour, M., Perl, S., Tisdale, J., et al. (2014). Neurogenesis in the striatum of the adult human brain. Cell 156, 1072-1083. doi: 10.1016/j.cell.2014.01.044

Etxeberria, A., Mangin, J.-M., Aguirre, A., and Gallo, V. (2010). Adult-born SVZ progenitors receive transient glutamatergic synapses during remyelination of the corpus callosum. Nat. Neurosci. 13, 287-289. doi: 10.1038/nn.2500

Fewtrell, C. (1993). $\mathrm{Ca}^{2+}$ oscillations in non-excitable cells. Annu. Rev. Physiol. 55, 427-454. doi: 10.1146/annurev.ph.55.030193.002235

Friedmann-Morvinski, D., Bushong, E. A., Ke, E., Soda, Y., Marumoto, T., Singer, O., et al. (2012). Dedifferentiation of neurons and astrocytes by oncogenes can induce gliomas in mice. Science 338, 1080-1084. doi: 10.1126/science.1226929

Galli, R., Binda, E., Orfanelli, U., Cipelletti, B., Gritti, A., De Vitis, S., et al. (2004). Isolation and characterization of tumorigenic, stem-like neural precursors from human glioblastoma. Cancer Res. 64, 7011-7021. doi: 10.1158/0008-5472.CAN04-1364

Garcia, G. C. T., and Dhermain, F. G. (2018). The subventricular zone concept: ready for therapeutic implications? Neurooncology 20, 1423-1424. doi: 10.1093/neuonc/noy147

Garcia, A. D. R., Doan, N. B., Imura, T., Bush, T. G., and Sofroniew, M. V. (2004). GFAP-expressing progenitors are the principal source of constitutive neurogenesis in adult mouse forebrain. Nat. Neurosci. 7, 1233-1241. doi: $10.1038 / \mathrm{nn} 1340$

García-González, D., Khodosevich, K., Watanabe, Y., Rollenhagen, A., Lübke, J. H. R., and Monyer, H. (2017). Serotonergic projections govern postnatal neuroblast migration. Neuron 94, 534.e9-549.e9. doi: 10.29252/ibj. 24.5.263

Genzen, J. R., Platel, J.-C., Rubio, M. E., and Bordey, A. (2009). Ependymal cells along the lateral ventricle express functional $\mathrm{P} 2 \mathrm{X}(7)$ receptors. Purinergic Signal. 5, 299-307. doi: 10.1007/s11302-009-9143-5

Gheorghe, M., Snoeck, M., Emmerich, M., Bäck, T., Goeman, J. J., and Raz, V. (2014). Major aging-associated RNA expressions change at two distinct agepositions. BMC Genomics 15:132. doi: 10.1186/1471-2164-15-132

Gheusi, G., Cremer, H., McLean, H., Chazal, G., Vincent, J. D., and Lledo, P. M. (2000). Importance of newly generated neurons in the adult olfactory bulb for odor discrimination. Proc. Natl. Acad. Sci. U S A 97, 1823-1828. doi: $10.1073 /$ pnas.97.4.1823

Gheusi, G., and Lledo, P.-M. (2014). Adult neurogenesis in the olfactory system shapes odor memory and perception. Prog. Brain Res. 208, 157-175. doi: 10.1016/B978-0-444-63350-7.00006-1

Ginisty, A., Gély-Pernot, A., Abaamrane, L., Morel, F., Arnault, P., Coronas, V., et al. (2015). Evidence for a subventricular zone neural stem cell phagocytic activity stimulated by the vitamin K-dependent factor protein S. Stem Cells 33, 515-525. doi: 10.1002/stem.1862

Giorgi-Gerevini, V. D., Melchiorri, D., Battaglia, G., Ricci-Vitiani, L., Ciceroni, C., Busceti, C. L., et al. (2005). Endogenous activation of metabotropic glutamate receptors supports the proliferation and survival of neural progenitor cells. Cell Death Differ. 12, 1124-1133. doi: 10.1038/sj.cdd.4401639

Glass, R., Synowitz, M., Kronenberg, G., Walzlein, J.-H., Markovic, D. S., Wang, L.-P., et al. (2005). Glioblastoma-induced attraction of endogenous neural precursor cells is associated with improved survival. J. Neurosci. 25, 2637-2646. doi: 10.1523/JNEUROSCI.5118-04.2005

González-Cobos, J. C., Zhang, X., Zhang, W., Ruhle, B., Motiani, R. K., Schindl, R., et al. (2013). Store-independent Orail/3 channels activated by intracrine leukotriene C4: role in neointimal hyperplasia. Circ. Res. 112, 1013-1025. doi: 10.1016/j.ejogrb.2020.06.039

Gonzalez-Perez, O. (2012). Neural stem cells in the adult human brain. Biol. Biomed. Rep. 2, 59-69.

Gould, E., Reeves, A. J., Fallah, M., Tanapat, P., Gross, C. G., and Fuchs, E. (1999). Hippocampal neurogenesis in adult Old World primates. Proc. Natl. Acad. Sci. U S A 96, 5263-5267. doi: 10.1073/pnas.96.9.5263

Gould, E., Tanapat, P., McEwen, B. S., Flügge, G., and Fuchs, E. (1998). Proliferation of granule cell precursors in the dentate gyrus of adult monkeys is diminished by stress. Proc. Natl. Acad. Sci. U S A 95, 3168-3171. doi: $10.1073 /$ pnas.95.6.3168

Guilak, F., Leddy, H. A., and Liedtke, W. (2010). Transient receptor potential vanilloid 4: the sixth sense of the musculoskeletal system? Ann. N. Y. Acad. Sci. 1192, 404-409. doi: 10.1111/j.1749-6632.2010.05389.x
Gutova, M., Flores, L., Adhikarla, V., Tsaturyan, L., Tirughana, R., Aramburo, S., et al. (2019). Quantitative evaluation of intraventricular delivery of therapeutic neural stem cells to orthotopic glioma. Front. Oncol. 9:68. doi: 10.3389/fonc. 2019.00068

Harraz, O. F., and Altier, C. (2014). STIM1-mediated bidirectional regulation of $\mathrm{Ca}^{2+}$ entry through voltage-gated calcium channels (VGCC) and calcium-release activated channels (CRAC). Front. Cell. Neurosci. 8:43. doi: $10.3389 /$ fncel.2014.00043

Hofmann, T., Obukhov, A. G., Schaefer, M., Harteneck, C., Gudermann, T., and Schultz, G. (1999). Direct activation of human TRPC6 and TRPC3 channels by diacylglycerol. Nature 397, 259-263. doi: 10.1038/16711

Hogan, P. G., Chen, L., Nardone, J., and Rao, A. (2003). Transcriptional regulation by calcium, calcineurin and NFAT. Genes Dev. 17, 2205-2232. doi: 10.1101/gad. 1102703

Holland, E. C., Celestino, J., Dai, C., Schaefer, L., Sawaya, R. E., and Fuller, G. N. (2000). Combined activation of Ras and Akt in neural progenitors induces glioblastoma formation in mice. Nat. Genet. 25, 55-57. doi: 10.1038/75596

Huang, G. N., Zeng, W., Kim, J. Y., Yuan, J. P., Han, L., Muallem, S., et al. (2006). STIM1 carboxyl-terminus activates native SOC, $\mathrm{I}_{\text {crac }}$ and TRPC1 channels. Nat. Cell Biol. 8, 1003-1010. doi: 10.1038/ncb1454

Imura, T., Kornblum, H. I., and Sofroniew, M. V. (2003). The predominant neural stem cell isolated from postnatal and adult forebrain but not early embryonic forebrain expresses GFAP. J. Neurosci. 23, 2824-2832. doi: 10.1523/JNEUROSCI.23-07-02824.2003

Jacques, T. S., Swales, A., Brzozowski, M. J., Henriquez, N. V., Linehan, J. M., Mirzadeh, Z., et al. (2010). Combinations of genetic mutations in the adult neural stem cell compartment determine brain tumour phenotypes. EMBO J. 29, 222-235. doi: 10.1038/emboj.2009.327

Jardin, I., Lopez, J. J., Salido, G. M., and Rosado, J. A. (2008). Orail mediates the interaction between STIM1 and hTRPC1 and regulates the mode of activation of hTRPC1-forming $\mathrm{Ca}^{2+}$ channels. J. Biol. Chem. 283, 25296-25304. doi: 10.1074/jbc.M802904200

Jarvis, M. F., and Khakh, B. S. (2009). ATP-gated P2X cation-channels. Neuropharmacology 56, 208-215. doi: 10.1016/j.neuropharm.2008.06.067

Jiang, Y., Song, Y., Wang, R., Hu, T., Zhang, D., Wang, Z., et al. (2019). NFAT1mediated regulation of NDEL1 promotes growth and invasion of glioma stem-like cells. Cancer Res. 79, 2593-2603. doi: 10.1158/0008-5472.CAN18-3297

Jin, K., Sun, Y., Xie, L., Peel, A., Mao, X. O., Batteur, S., et al. (2003). Directed migration of neuronal precursors into the ischemic cerebral cortex and striatum. Mol. Cell. Neurosci. 24, 171-189. doi: 10.1016/s1044-7431(03)00159-3

Jin, K., Wang, X., Xie, L., Mao, X. O., and Greenberg, D. A. (2010). Transgenic ablation of doublecortin-expressing cells suppresses adult neurogenesis and worsens stroke outcome in mice. Proc. Natl. Acad. Sci. U S A 107, 7993-7998. doi: 10.1073/pnas.1000154107

Jin, K., Wang, X., Xie, L., Mao, X. O., Zhu, W., Wang, Y., et al. (2006). Evidence for stroke-induced neurogenesis in the human brain. Proc. Natl. Acad. Sci. US A 103, 13198-13202. doi: 10.1073/pnas.0603512103

Kalamakis, G., Brüne, D., Ravichandran, S., Bolz, J., Fan, W., Ziebell, F., et al. (2019). Quiescence modulates stem cell maintenance and regenerative capacity in the aging brain. Cell 176, 1407-1419. doi: 10.1016/j.cell.2019. 01.040

Kempermann, G., Gage, F. H., Aigner, L., Song, H., Curtis, M., Thuret, S., et al. (2018). Human adult neurogenesis: evidence and remaining questions. Cell Stem Cell 23, 25-30. doi: 10.1016/j.stem.2018.04.004

Khatri, P., Obernier, K., Simeonova, I. K., Hellwig, A., Hölzl-Wenig, G., Mandl, C., et al. (2014). Proliferation and cilia dynamics in neural stem cells prospectively isolated from the SEZ. Sci. Rep. 4:3803. doi: 10.1038/srep 03803

Khodosevich, K., Seeburg, P. H., and Monyer, H. (2009). Major signaling pathways in migrating neuroblasts. Front. Mol. Neurosci. 2:7. doi: 10.3389/neuro.02. 007.2009

Kokoeva, M. V., Yin, H., and Flier, J. S. (2005). Neurogenesis in the hypothalamus of adult mice: potential role in energy balance. Science 310, 679-683. doi: $10.1126 /$ science. 1115360

Kong, H., Fan, Y., Xie, J., Ding, J., Sha, L., Shi, X., et al. (2008). AQP4 knockout impairs proliferation, migration and neuronal differentiation of adult neural stem cells. J. Cell. Sci. 121, 4029-4036. doi: 10.1242/jcs.035758 
Kornack, D. R., and Rakic, P. (1999). Continuation of neurogenesis in the hippocampus of the adult macaque monkey. Proc. Natl. Acad. Sci. U S A 96, 5768-5773. doi: 10.1073/pnas.96.10.5768

Kornack, D. R., and Rakic, P. (2001). The generation, migration and differentiation of olfactory neurons in the adult primate brain. Proc. Natl. Acad. Sci. U S A 98, 4752-4757. doi: 10.1073/pnas.081074998

Kraft, A., Jubal, E. R., von Laer, R., Döring, C., Rocha, A., Grebbin, M., et al. (2017). Astrocytic calcium waves signal brain injury to neural stem and progenitor cells. Stem Cell Rep. 8, 701-714. doi: 10.1016/j.stemcr.2017.01.009

Kumar, A., Bodhinathan, K., and Foster, T. C. (2009). Susceptibility to calcium dysregulation during brain aging. Front. Aging Neurosci. 1:2. doi: 10.3389/neuro.24.002.2009

Lacar, B., Young, S. Z., Platel, J.-C., and Bordey, A. (2011). Gap junction-mediated calcium waves define communication networks among murine postnatal neural progenitor cells. Eur. J. Neurosci. 34, 1895-1905. doi: 10.1111/j.14609568.2011.07901.x

Lazarov, O., and Marr, R. A. (2013). Of mice and men: neurogenesis, cognition and Alzheimer's disease. Front. Aging Neurosci. 5:43. doi: 10.3389/fnagi.2013. 00043

Lee, J. H., Lee, J. E., Kahng, J. Y., Kim, S. H., Park, J. S., Yoon, S. J., et al. (2018). Human glioblastoma arises from subventricular zone cells with low-level driver mutations. Nature 560, 243-247. doi: 10.1038/s41586-018-0389-3

Lee, K. P., Yuan, J. P., So, I., Worley, P. F., and Muallem, S. (2010). STIM1dependent and STIM1-independent function of transient receptor potential canonical (TRPC) channels tunes their store-operated mode. J. Biol. Chem. 285, 38666-38673. doi: 10.1074/jbc.M110.155036

Leeson, H. C., Kasherman, M. A., Chan-Ling, T., Lovelace, M. D., Brownlie, J. C., Toppinen, K. M., et al. (2018). P2X7 receptors regulate phagocytosis and proliferation in adult hippocampal and SVZ neural progenitor cells: implications for inflammation in neurogenesis. Stem Cells 36, 1764-1777. doi: 10.1002/stem.2894

Liberati, S., Morelli, M. B., Amantini, C., Santoni, M., Nabissi, M., Cardinali, C., et al. (2014). Advances in transient receptor potential vanilloid-2 channel expression and function in tumor growth and progression. Curr. Protein Pept. Sci. 15, 732-737. doi: 10.2174/1389203715666140704115913

Lim, D. A., and Alvarez-Buylla, A. (2016). The adult ventricular-subventricular zone (V-SVZ) and olfactory bulb (OB) neurogenesis. Cold Spring. Harb. Perspect. Biol. 8:a018820. doi: 10.1101/cshperspect.a018820

Lindberg, N., Kastemar, M., Olofsson, T., Smits, A., and Uhrbom, L. (2009). Oligodendrocyte progenitor cells can act as cell of origin for experimental glioma. Oncogene 28, 2266-2275. doi: 10.1038/onc.2009.76

Lintschinger, B., Balzer-Geldsetzer, M., Baskaran, T., Graier, W. F., Romanin, C., Zhu, M. X., et al. (2000). Coassembly of Trp1 and Trp3 proteins generates diacylglycerol- and $\mathrm{Ca}^{2+}$-sensitive cation channels. J. Biol. Chem. 275, 27799-27805. doi: 10.1074/jbc.M002705200

Liu, C., Sage, J. C., Miller, M. R., Verhaak, R. G. W., Hippenmeyer, S., Vogel, H., et al. (2011). Mosaic analysis with double markers reveals tumor cell of origin in glioma. Cell 146, 209-221. doi: 10.1016/j.cell.2011.06.014

Liu, X., Bandyopadhyay, B. C., Singh, B. B., Groschner, K., and Ambudkar, I. S. (2005a). Molecular analysis of a store-operated and 2-acetyl-sn-glycerolsensitive non-selective cation channel. Heteromeric assembly of TRPC1TRPC3. J. Biol. Chem. 280, 21600-21606. doi: 10.1074/jbc.C4004 92200

Liu, X., Wang, Q., Haydar, T. F., and Bordey, A. (2005b). Nonsynaptic GABA signaling in postnatal subventricular zone controls proliferation of GFAP-expressing progenitors. Nat. Neurosci. 8, 1179-1187. doi: $10.1038 / \mathrm{nn} 1522$

Lledo, P.-M., and Valley, M. (2016). Adult olfactory bulb neurogenesis. Cold Spring Harb. Perspect. Biol. 8:a018945. doi: 10.1101/cshperspect.a018945

Lodge, D. (2009). The history of the pharmacology and cloning of ionotropic glutamate receptors and the development of idiosyncratic nomenclature. Neuropharmacology 56, 6-21. doi: 10.1016/j.neuropharm.2008.08.006

Lodola, F., Laforenza, U., Bonetti, E., Lim, D., Dragoni, S., Bottino, C., et al. (2012). Store-operated $\mathrm{Ca}^{2+}$ entry is remodelled and controls in vitro angiogenesis in endothelial progenitor cells isolated from tumoral patients. PLoS One 7:e42541. doi: 10.1371/journal.pone.0042541

Lois, C., and Alvarez-Buylla, A. (1994). Long-distance neuronal migration in the adult mammalian brain. Science 264, 1145-1148. doi: 10.1126/science.8178174
Lois, C., García-Verdugo, J. M., and Alvarez-Buylla, A. (1996). Chain migration of neuronal precursors. Science 271, 978-981. doi: 10.1126/science.271.5251.978

Lopez, J. J., Jardin, I., Sanchez-Collado, J., Salido, G. M., Smani, T., and Rosado, J. A. (2020). TRPC Channels in the SOCE Scenario. Cells 9:126. doi: $10.3390 /$ cells 9010126

Lu, Z., Elliott, M. R., Chen, Y., Walsh, J. T., Klibanov, A. L., Ravichandran, K. S., et al. (2011). Phagocytic activity of neuronal progenitors regulates adult neurogenesis. Nat. Cell Biol. 13, 1076-1083. doi: 10.1038/ncb2299

Luskin, M. B. (1993). Restricted proliferation and migration of postnatally generated neurons derived from the forebrain subventricular zone. Neuron 11 , 173-189. doi: 10.1016/0896-6273(93)90281-u

Lynch, J. W. (2009). Native glycine receptor subtypes and their physiological roles. Neuropharmacology 56, 303-309. doi: 10.1016/j.neuropharm.2008.07.034

Macas, J., Nern, C., Plate, K. H., and Momma, S. (2006). Increased generation of neuronal progenitors after ischemic injury in the aged adult human forebrain. J. Neurosci. 26, 13114-13119. doi: 10.1523/JNEUROSCI.4667-06.2006

MacDougall, M. S., Clarke, R., and Merrill, B. J. (2019). Intracellular $\mathrm{Ca}^{2+}$ homeostasis and nuclear export mediate exit from naive pluripotency. Cell Stem Cell 25, 210.e6-224.e6. doi: 10.1016/j.stem.2019.04.015

Martí-Fàbregas, J., Romaguera-Ros, M., Gómez-Pinedo, U., Martínez-Ramírez, S., Jiménez-Xarrié, E., Marín, R., et al. (2010). Proliferation in the human ipsilateral subventricular zone after ischemic stroke. Neurology 74, 357-365. doi: 10.2215/CJN.09330819

Marumoto, T., Tashiro, A., Friedmann-Morvinski, D., Scadeng, M., Soda, Y., Gage, F. H., et al. (2009). Development of a novel mouse glioma model using lentiviral vectors. Nat. Med. 15, 110-116. doi: 10.1038/nm.1863

Maslov, A. Y., Barone, T. A., Plunkett, R. J., and Pruitt, S. C. (2004). Neural stem cell detection, characterization, and age-related changes in the subventricular zone of mice. J. Neurosci. 24, 1726-1733. doi: 10.1523/JNEUROSCI.460803.2004

Maslyukov, A., Li, K., Su, X., Kovalchuk, Y., and Garaschuk, O. (2018). Spontaneous calcium transients in the immature adult-born neurons of the olfactory bulb. Cell Calcium 74, 43-52. doi: 10.1016/j.ceca.2018.06.001

Matarredona, E. R., and Pastor, A. M. (2019). Neural stem cells of the subventricular zone as the origin of human glioblastoma stem cells. Therapeutic implications. Front. Oncol. 9:779. doi: 10.3389/fonc.2019.00779

Mattson, M. P., and Arumugam, T. V. (2018). Hallmarks of brain aging: adaptive and pathological modification by metabolic states. Cell Metab. 27, 1176-1199. doi: 10.1016/j.cmet.2018.05.011

Menn, B., Garcia-Verdugo, J. M., Yaschine, C., Gonzalez-Perez, O., Rowitch, D., and Alvarez-Buylla, A. (2006). Origin of oligodendrocytes in the subventricular zone of the adult brain. J. Neurosci. 26, 7907-7918. doi: 10.1523/JNEUROSCI. 1299-06.2006

Messemer, N., Kunert, C., Grohmann, M., Sobottka, H., Nieber, K., Zimmermann, H., et al. (2013). P2X7 receptors at adult neural progenitor cells of the mouse subventricular zone. Neuropharmacology 73, 122-137. doi: 10.1016/j.neuropharm.2013.05.017

Migaud, M., Batailler, M., Segura, S., Duittoz, A., Franceschini, I., and Pillon, D. (2010). Emerging new sites for adult neurogenesis in the mammalian brain: a comparative study between the hypothalamus and the classical neurogenic zones. Eur. J. Neurosci. 32, 2042-2052. doi: 10.1111/j.1460-9568.2010.07521.x

Mikoshiba, K. (2015). Role of IP3 receptor signaling in cell functions and diseases. Adv. Biol. Regul. 57, 217-227. doi: 10.1016/j.jbior.2014.10.001

Millar, N. S., and Gotti, C. (2009). Diversity of vertebrate nicotinic acetylcholine receptors. Neuropharmacology 56, 237-246. doi: 10.1016/j.neuropharm.2008. 07.041

Mirzadeh, Z., Merkle, F. T., Soriano-Navarro, M., García-Verdugo, J. M., and Alvarez-Buylla, A. (2008). Neural stem cells confer unique pinwheel architecture to the ventricular surface in neurogenic regions of the adult brain. Cell Stem Cell 3, 265-278. doi: 10.1016/j.stem.2008.07.004

Moccia, F., Negri, S., Faris, P., and Berra-Romani, R. (2020). Targeting the endothelial $\mathrm{Ca}^{2+}$ toolkit to rescue endothelial dysfunction in obesity associated-hypertension. Curr. Med. Chem. 27, 240-257. doi: 10.2174/0929867326666190905142135

Morelli, M. B., Nabissi, M., Amantini, C., Farfariello, V., Ricci-Vitiani, L., di Martino, S., et al. (2012). The transient receptor potential vanilloid-2 cation channel impairs glioblastoma stem-like cell proliferation and promotes differentiation. Int. J. Cancer 131, E1067-E1077. doi: 10.1002/ijc.27588 
Motiani, R. K., Abdullaev, I. F., and Trebak, M. (2010). A novel native store-operated calcium channel encoded by Orai3: selective requirement of Orai3 versus Orail in estrogen receptor-positive versus estrogen receptornegative breast cancer cells. J. Biol. Chem. 285, 19173-19183. doi: 10.1074/jbc. M110.102582

Motiani, R. K., Hyzinski-García, M. C., Zhang, X., Henkel, M. M., Abdullaev, I. F., Kuo, Y.-H., et al. (2013). STIM1 and Orail mediate CRAC channel activity and are essential for human glioblastoma invasion. Pflugers Arch. 465, 1249-1260. doi: $10.1007 / \mathrm{s} 00424-013-1254-8$

Mudò, G., Belluardo, N., Mauro, A., and Fuxe, K. (2007). Acute intermittent nicotine treatment induces fibroblast growth factor- 2 in the subventricular zone of the adult rat brain and enhances neuronal precursor cell proliferation. Neuroscience 145, 470-483. doi: 10.1016/j.neuroscience.2006.12.012

Nait-Oumesmar, B., Picard-Riera, N., Kerninon, C., Decker, L., Seilhean, D., Höglinger, G. U., et al. (2007). Activation of the subventricular zone in multiple sclerosis: evidence for early glial progenitors. Proc. Natl. Acad. Sci. U S A 104, 4694-4699. doi: 10.1073/pnas.0606835104

Narla, S. T., Klejbor, I., Birkaya, B., Lee, Y.-W., Morys, J., Stachowiak, E. K., et al. (2013). Activation of developmental nuclear fibroblast growth factor receptor 1 signaling and neurogenesis in adult brain by $\alpha 7$ nicotinic receptor agonist. Stem Cells Transl. Med. 2, 776-788. doi: 10.5966/sctm.2012-0103

Niklasson, M., Maddalo, G., Sramkova, Z., Mutlu, E., Wee, S., Sekyrova, P., et al. (2017). Membrane-depolarizing channel blockers induce selective glioma cell death by impairing nutrient transport and unfolded protein/amino acid responses. Cancer Res. 77, 1741-1752. doi: 10.1158/0008-5472.CAN-16-2274

Nilius, B., and Appendino, G. (2013). Spices: the savory and beneficial science of pungency. Rev. Physiol. Biochem. Pharmacol. 164, 1-76. doi: 10.1007/112_2013_11

Nguyen, L., Malgrange, B., Breuskin, I., Bettendorff, L., Moonen, G., Belachew, S., et al. (2003). Autocrine/paracrine activation of the $\mathrm{GABA}_{(\mathrm{A})}$ receptor inhibits the proliferation of neurogenic polysialylated neural cell adhesion moleculepositive (PSA-NCAM+) precursor cells from postnatal striatum. J. Neurosci. 23, 3278-3294. doi: 10.1523/JNEUROSCI.23-08-03278.2003

North, R. A. (2016). P2X receptors. Philos. Trans. R. Soc. Lond. B Biol. Sci. 371:20150427. doi: 10.1098/rstb.2015.0427

Nottebohm, F. (1985). Neuronal replacement in adulthood. Ann. N Y Acad. Sci. 457, 143-161. doi: 10.1111/j.1749-6632.1985.tb20803.x

Obernier, K., and Alvarez-Buylla, A. (2019). Neural stem cells: origin, heterogeneity and regulation in the adult mammalian brain. Development 146:dev156059. doi: 10.1242/dev.156059

Obernier, K., Cebrian-Silla, A., Thomson, M., Parraguez, J. I., Anderson, R., Guinto, C., et al. (2018). Adult neurogenesis is sustained by symmetric self-renewal and differentiation. Cell Stem Cell 22, 221.e8-234.e8. doi: $10.1016 /$ j.stem.2018.01.003

Oh, M. C., Kim, J. M., Safaee, M., Kaur, G., Sun, M. Z., Kaur, R., et al. (2012). Overexpression of calcium-permeable glutamate receptors in glioblastoma derived brain tumor initiating cells. PLoS One 7:e47846. doi: 10.1371/journal. pone. 0047846

Olsen, R. W., and Sieghart, W. (2008). International Union of Pharmacology. LXX. Subtypes of gamma-aminobutyric acid(A) receptors: classification on the basis of subunit composition, pharmacology, and function. Update. Pharmacol. Rev. 60, 243-260. doi: 10.1124/pr.108.00505

Omuro, A., Beal, K., McNeill, K., Young, R. J., Thomas, A., Lin, X., et al. (2018). Multicenter phase IB trial of carboxyamidotriazole orotate and temozolomide for recurrent and newly diagnosed glioblastoma and other anaplastic gliomas. J. Clin. Oncol. 36, 1702-1709. doi: 10.1200/JCO.2017.76.9992

Ortega, F., Gascón, S., Masserdotti, G., Deshpande, A., Simon, C., Fischer, J., et al. (2013). Oligodendrogliogenic and neurogenic adult subependymal zone neural stem cells constitute distinct lineages and exhibit differential responsiveness to Wnt signalling. Nat. Cell Biol. 15, 602-613. doi: 10.1038/ ncb2736

Paez-Gonzalez, P., Asrican, B., Rodriguez, E., and Kuo, C. T. (2014). Identification of distinct $\mathrm{ChAT}^{+}$neurons and activity-dependent control of postnatal SVZ neurogenesis. Nat. Neurosci. 17, 934-942. doi: 10.1038/ nn. 3734

Palmer, T. D., Takahashi, J., and Gage, F. H. (1997). The adult rat hippocampus contains primordial neural stem cells. Mol. Cell. Neurosci. 8, 389-404. doi: 10.1006/mcne.1996.0595
Paredes, M. F., James, D., Gil-Perotin, S., Kim, H., Cotter, J. A., Ng, C., et al. (2016). Extensive migration of young neurons into the infant human frontal lobe. Science 354:aaf7073. doi: 10.1126/science.aaf7073

Parekh, A. B., and Putney, J. W. (2005). Store-operated calcium channels. Physiol. Rev. 85, 757-810. doi: 10.1152/physrev.00057.2003

Parent, J. M., Vexler, Z. S., Gong, C., Derugin, N., and Ferriero, D. M. (2002). Rat forebrain neurogenesis and striatal neuron replacement after focal stroke. Ann. Neurol. 52, 802-813. doi: 10.1002/ana.10393

Patapoutian, A., Tate, S., and Woolf, C. J. (2009). Transient receptor potential channels: targeting pain at the source. Nat. Rev. Drug Discov. 8, 55-68. doi: $10.1038 / \mathrm{nrd} 2757$

Pedersen, S. F., and Nilius, B. (2007). Transient receptor potential channels in mechanosensing and cell volume regulation. Methods Enzymol. 428, 183-207. doi: 10.1016/S0076-6879(07)28010-3

Petreanu, L., and Alvarez-Buylla, A. (2002). Maturation and death of adult-born olfactory bulb granule neurons: role of olfaction. J. Neurosci. 22, 6106-6113. doi: 10.1523/JNEUROSCI.22-14-06106.2002

Petrik, D., Myoga, M. H., Grade, S., Gerkau, N. J., Pusch, M., Rose, C. R., et al. (2018). Epithelial sodium channel regulates adult neural stem cell proliferation in a flow-dependent manner. Cell Stem Cell 22, 865.e8-878.e8. doi: 10.1016/j. stem.2018.04.016

Picard-Riera, N., Decker, L., Delarasse, C., Goude, K., Nait-Oumesmar, B., Liblau, R., et al. (2002). Experimental autoimmune encephalomyelitis mobilizes neural progenitors from the subventricular zone to undergo oligodendrogenesis in adult mice. Proc. Natl. Acad. Sci. U S A 99, 13211-13216. doi: 10.1073/pnas.192314199

Platel, J. C., Dave, K. A., and Bordey, A. (2008). Control of neuroblast production and migration by converging GABA and glutamate signals in the postnatal forebrain. J. Physiol. 586, 3739-3743. doi: 10.1113/jphysiol.2008. 155325

Platel, J.-C., Dave, K. A., Gordon, V., Lacar, B., Rubio, M. E., and Bordey, A. (2010). NMDA receptors activated by subventricular zone astrocytic glutamate are critical for neuroblast survival prior to entering a synaptic network. Neuron 65, 859-872. doi: 10.1016/j.neuron.2010.03.009

Ponti, G., Obernier, K., Guinto, C., Jose, L., Bonfanti, L., and Alvarez-Buylla, A. (2013). Cell cycle and lineage progression of neural progenitors in the ventricular-subventricular zones of adult mice. Proc. Natl. Acad. Sci. U S A 110, E1045-E1054. doi: 10.1073/pnas.1219563110

Popugaeva, E., Pchitskaya, E., and Bezprozvanny, I. (2018). Dysregulation of intracellular calcium signaling in Alzheimer's disease. Antioxid. Redox Signal. 29, 1176-1188. doi: 10.1089/ars.2018.7506

Portnow, J., Synold, T. W., Badie, B., Tirughana, R., Lacey, S. F., D’Apuzzo, M., et al. (2017). Neural stem cell-based anticancer gene therapy: a first-in-human study in recurrent high-grade glioma patients. Clin. Cancer Res. 23, 2951-2960. doi: 10.1158/1078-0432.CCR-16-1518

Poteser, M., Graziani, A., Rosker, C., Eder, P., Derler, I., Kahr, H., et al. (2006). TRPC3 and TRPC4 associate to form a redox-sensitive cation channel. Evidence for expression of native TRPC3-TRPC4 heteromeric channels in endothelial cells. J. Biol. Chem. 281, 13588-13595. doi: 10.1074/jbc. M512205200

Prevarskaya, N., Skryma, R., and Shuba, Y. (2010). Ion channels and the hallmarks of cancer. Trends Mol. Med. 16, 107-121. doi: 10.1016/j.molmed.2010.01.005

Prevarskaya, N., Skryma, R., and Shuba, Y. (2018). Ion channels in cancer: are cancer hallmarks oncochannelopathies? Physiol. Rev. 98, 559-621. doi: $10.1152 /$ physrev.00044.2016

Puchaowicz, K., Tarnowski, M., Baranowska-Bosiacka, I., Chlubek, D., and Dziedziejko, V. (2014). P2X and P2Y receptors-role in the pathophysiology of the nervous system. Int. J. Mol. Sci. 15, 23672-23704. doi: 10.22203/eCM. v037a04

Quiñones-Hinojosa, A., and Chaichana, K. (2007). The human subventricular zone: a source of new cells and a potential source of brain tumors. Exp. Neurol. 205, 313-324. doi: 10.1016/j.expneurol.2007.03.016

Quiñones-Hinojosa, A., Sanai, N., Soriano-Navarro, M., Gonzalez-Perez, O., Mirzadeh, Z., Gil-Perotin, S., et al. (2006). Cellular composition and cytoarchitecture of the adult human subventricular zone: a niche of neural stem cells. J. Comp. Neurol. 494, 415-434. doi: 10.1039/d0cp04354k

Raponi, E., Agenes, F., Delphin, C., Assard, N., Baudier, J., Legraverend, C., et al. (2007). S100B expression defines a state in which GFAP-expressing cells lose 
their neural stem cell potential and acquire a more mature developmental stage. Glia 55, 165-177. doi: 10.1002/glia.20445

Recht, L., Jang, T., Savarese, T., and Litofsky, N. S. (2003). Neural stem cells and neuro-oncology: quo vadis? J. Cell. Biochem. 88, 11-19. doi: 10.1002/jcb.10208

Reynolds, B. A., Tetzlaff, W., and Weiss, S. (1992). A multipotent EGF-responsive striatal embryonic progenitor cell produces neurons and astrocytes. J. Neurosci. 12, 4565-4574. doi: 10.1523/JNEUROSCI.12-11-04565.1992

Roberts, J. C., Davis, J. B., and Benham, C. D. (2004). [3H]Resiniferatoxin autoradiography in the CNS of wild-type and TRPV1 null mice defines TRPV1 (VR-1) protein distribution. Brain Res. 995, 176-183. doi: 10.1016/j.brainres. 2003.10.001

Robil, N., Petel, F., Kilhoffer, M.-C., and Haiech, J. (2015). Glioblastoma and calcium signaling-analysis of calcium toolbox expression. Int. J. Dev. Biol. 59, 407-415. doi: 10.1387/ijdb.150200jh

Sabourin, J., Harisseh, R., Harnois, T., Magaud, C., Bourmeyster, N., Déliot, N., et al. (2012). Dystrophin/ $\alpha 1$-syntrophin scaffold regulated PLC/PKCdependent store-operated calcium entry in myotubes. Cell Calcium 52, 445-456. doi: 10.1016/j.ceca.2012.08.003

Sabourin, J., Lamiche, C., Vandebrouck, A., Magaud, C., Rivet, J., Cognard, C., et al. (2009). Regulation of TRPC1 and TRPC4 cation channels requires an alpha1-syntrophin-dependent complex in skeletal mouse myotubes. J. Biol. Chem. 284, 36248-36261. doi: 10.1074/jbc.M109.012872

Samanta, K., and Parekh, A. B. (2017). Spatial $\mathrm{Ca}^{2+}$ profiling: decrypting the universal cytosolic $\mathrm{Ca}^{2+}$ oscillation. J. Physiol. 595, 3053-3062. doi: $10.1113 / J P 272860$

Sanai, N., Nguyen, T., Ihrie, R. A., Mirzadeh, Z., Tsai, H.-H., Wong, M., et al. (2011). Corridors of migrating neurons in human brain and their decline during infancy. Nature 478, 382-386. doi: 10.1038/nature10487

Sanai, N., Tramontin, A. D., Quiñones-Hinojosa, A., Barbaro, N. M., Gupta, N., Kunwar, S., et al. (2004). Unique astrocyte ribbon in adult human brain contains neural stem cells but lacks chain migration. Nature 427, 740-744. doi: 10.1038/nature02301

Santulli, G., Lewis, D., des Georges, A., Marks, A. R., and Frank, J. (2018). Ryanodine receptor structure and function in health and disease. Subcell. Biochem. 87, 329-352. doi: 10.1007/978-981-10-7757-9_11

Schwaller, B. (2010). Cytosolic $\mathrm{Ca}^{2+}$ buffers. Cold Spring Harb. Perspect. Biol. 2:a004051. doi: 10.1101/cshperspect.a004051

Serrano-Pérez, M. C., Fernández, M., Neria, F., Berjón-Otero, M., DoncelPérez, E., Cano, E., et al. (2015). NFAT transcription factors regulate survival, proliferation, migration and differentiation of neural precursor cells. Glia 63, 987-1004. doi: 10.1097/QAD.0000000000002728

Sharma, G. (2013). The dominant functional nicotinic receptor in progenitor cells in the rostral migratory stream is the $\alpha 3 \beta 4$ subtype. J. Neurophysiol. 109, 867-872. doi: 10.1152/jn.00886.2012

Shi, J., Parada, L. F., and Kernie, S. G. (2005). Bax limits adult neural stem cell persistence through caspase and IP3 receptor activation. Cell Death Differ. 12, 1601-1612. doi: 10.1038/sj.cdd.4401676

Shin, D. M., Son, A., Park, S., Kim, M. S., Ahuja, M., and Muallem, S. (2016). The TRPCs, Orais and STIMs in ER/PM junctions. Adv. Exp. Med. Biol. 898, 47-66. doi: 10.1007/978-3-319-26974-0_3

Shook, B. A., Manz, D. H., Peters, J. J., Kang, S., and Conover, J. C. (2012). Spatiotemporal changes to the subventricular zone stem cell pool through aging. J. Neurosci. 32, 6947-6956. doi: 10.1523/JNEUROSCI.5987-11.2012

Shuttleworth, T. J. (2009). Arachidonic acid, ARC channels and Orai proteins. Cell Calcium 45, 602-610. doi: 10.1016/j.ceca.2009.02.001

Singh, S. K., Hawkins, C., Clarke, I. D., Squire, J. A., Bayani, J., Hide, T., et al. (2004). Identification of human brain tumour initiating cells. Nature 432, 396-401. doi: 10.1038/nature03128

Skibinska-Kijek, A., Wisniewska, M. B., Gruszczynska-Biegala, J., Methner, A., and Kuznicki, J. (2009). Immunolocalization of STIM1 in the mouse brain. Acta Neurobiol. Exp. 69, 413-428.

Snethen, H., Love, S., and Scolding, N. (2008). Disease-responsive neural precursor cells are present in multiple sclerosis lesions. Regener. Med. 3, 835-847. doi: 10.2217/17460751.3.6.835

Sohn, J., Orosco, L., Guo, F., Chung, S.-H., Bannerman, P., Mills Ko, E., et al. (2015). The subventricular zone continues to generate corpus callosum and rostral migratory stream astroglia in normal adult mice. J. Neurosci. 35, 3756-3763. doi: 10.1523/JNEUROSCI.3454-14.2015
Somasundaram, A., Shum, A. K., McBride, H. J., Kessler, J. A., Feske, S., Miller, R. J., et al. (2014). Store-operated CRAC channels regulate gene expression and proliferation in neural progenitor cells. J. Neurosci. 34, 9107-9123. doi: 10.1523/JNEUROSCI.0263-14.2014

Song, Y., Jiang, Y., Tao, D., Wang, Z., Wang, R., Wang, M., et al. (2020). NFAT2HDAC1 signaling contributes to the malignant phenotype of glioblastoma. Neuro Oncol. 22, 46-57. doi: 10.1093/neuonc/noz136

Song, M., Yu, S. P., Mohamad, O., Cao, W., Wei, Z. Z., Gu, X., et al. (2017). Optogenetic stimulation of glutamatergic neuronal activity in the striatum enhances neurogenesis in the subventricular zone of normal and stroke mice. Neurobiol. Dis. 98, 9-24. doi: 10.1016/j.nbd.2016.11.005

Sorrells, S. F., Paredes, M. F., Cebrian-Silla, A., Sandoval, K., Qi, D., Kelley, K. W., et al. (2018). Human hippocampal neurogenesis drops sharply in children to undetectable levels in adults. Nature 555, 377-381. doi: 10.1038/nature 25975

Spalding, K. L., Bergmann, O., Alkass, K., Bernard, S., Salehpour, M., Huttner, H. B., et al. (2013). Dynamics of hippocampal neurogenesis in adult humans. Cell 153, 1219-1227. doi: 10.1016/j.cell.2013.05.002

Spina, R., Voss, D. M., Asnaghi, L., Sloan, A., and Bar, E. E. (2016). Atracurium Besylate and other neuromuscular blocking agents promote astroglial differentiation and deplete glioblastoma stem cells. Oncotarget 7 , 459-472. doi: 10.18632/oncotarget.6314

Stafford, M. R., Bartlett, P. F., and Adams, D. J. (2007). Purinergic receptor activation inhibits mitogen-stimulated proliferation in primary neurospheres from the adult mouse subventricular zone. Mol. Cell. Neurosci. 35, 535-548. doi: 10.1016/j.mcn.2007.04.013

Stock, K., Garthe, A., de Sassi, F. A., Glass, R., Wolf, S. A., and Kettenmann, H. (2014). The capsaicin receptor TRPV1 as a novel modulator of neural precursor cell proliferation. Stem Cells 32, 3183-3195. doi: 10.1002/stem.1805

Stupp, R., Mason, W. P., van den Bent, M. J., Weller, M., Fisher, B., Taphoorn, M. J. B., et al. (2005). Radiotherapy plus concomitant and adjuvant temozolomide for glioblastoma. N. Eng. J. Med. 352, 987-996. doi: 10.1056/NEJMoa043330

Sun, F., Wang, X., Mao, X., Xie, L., and Jin, K. (2012). Ablation of neurogenesis attenuates recovery of motor function after focal cerebral ischemia in middle-aged mice. PLoS One 7:e46326. doi: 10.1371/journal.pone.00 46326

Suyama, S., Sunabori, T., Kanki, H., Sawamoto, K., Gachet, C., Koizumi, S., et al. (2012). Purinergic signaling promotes proliferation of adult mouse subventricular zone cells. J. Neurosci. 32, 9238-9247. doi: 10.1523/JNEUROSCI.4001-11.2012

Tanwar, J., Arora, S., and Motiani, R. K. (2020). Orai3: Oncochannel with therapeutic potential. Cell Calcium 90:102247. doi: 10.1016/j.ceca.2020. 102247

Tejada Neyra, M. A., Neuberger, U., Reinhardt, A., Brugnara, G., Bonekamp, D., Sill, M., et al. (2018). Voxel-wise radiogenomic mapping of tumor location with key molecular alterations in patients with glioma. Neuro Oncol. 20, 1517-1524. doi: 10.1093/neuonc/noy134

Tepavčević, V., Lazarini, F., Alfaro-Cervello, C., Kerninon, C., Yoshikawa, K., Garcia-Verdugo, J. M., et al. (2011). Inflammation-induced subventricular zone dysfunction leads to olfactory deficits in a targeted mouse model of multiple sclerosis. J. Clin. Invest. 121, 4722-4734. doi: 10.1016/j.healthpol.2012. 03.004

Terrié, E., Coronas, V., and Constantin, B. (2019). Role of the calcium toolkit in cancer stem cells. Cell Calcium 80, 141-151. doi: 10.1016/j.ceca.2019.05.001

Tominaga, M. (2007). "The role of TRP channels in thermosensation," in TRP Ion Channel Function in Sensory Transduction and Cellular Signaling Cascades, eds. W. B. Liedtke and S. Heller (Boca Raton, FL: CRC Press/Taylor and Francis), Available online at: http://www.ncbi.nlm.nih.gov/books/NBK5244/. Accessed August 19, 2020

Tong, C. K., Han, Y.-G., Shah, J. K., Obernier, K., Guinto, C. D., and AlvarezBuylla, A. (2014). Primary cilia are required in a unique subpopulation of neural progenitors. Proc. Natl. Acad. Sci. U S A 111, 12438-12443. doi: 10.1073/pnas. 1321425111

Torres, Á., Erices, J. I., Sanchez, F., Ehrenfeld, P., Turchi, L., Virolle, T., et al. (2019). Extracellular adenosine promotes cell migration/invasion of glioblastoma stem-like cells through A3 adenosine receptor activation under hypoxia. Cancer Lett. 446, 112-122. doi: 10.1016/j.canlet.2019.01.004 
Vaeth, M., Yang, J., Yamashita, M., Zee, I., Eckstein, M., Knosp, C., et al. (2017). ORAI2 modulates store-operated calcium entry and T cell-mediated immunity. Nat. Commun. 8:14714. doi: 10.1038/ncomms 14714

Vazquez, G., Lievremont, J. P., St J Bird, G., and Putney, J. W. (2001). Human Trp3 forms both inositol trisphosphate receptor-dependent and receptorindependent store-operated cation channels in DT40 avian B lymphocytes. Proc. Natl. Acad. Sci. U S A 98, 11777-11782. doi: 10.1073/pnas.201238198

Venkatachalam, K., Zheng, F., and Gill, D. L. (2003). Regulation of canonical transient receptor potential (TRPC) channel function by diacylglycerol and protein kinase C. J. Biol. Chem. 278, 29031-29040. doi: 10.1074/jbc. M302751200

Venkataramani, V., Tanev, D. I., Strahle, C., Studier-Fischer, A., Fankhauser, L., Kessler, T., et al. (2019). Glutamatergic synaptic input to glioma cells drives brain tumour progression. Nature 573, 532-538. doi: 10.1038/s41586-0191564-x

Venkatesh, H. S., Morishita, W., Geraghty, A. C., Silverbush, D., Gillespie, S. M., Arzt, M., et al. (2019). Electrical and synaptic integration of glioma into neural circuits. Nature 573, 539-545. doi: 10.1038/s41586-019-1563-y

Wang, C., Liu, F., Liu, Y.-Y., Zhao, C.-H., You, Y., Wang, L., et al. (2011). Identification and characterization of neuroblasts in the subventricular zone and rostral migratory stream of the adult human brain. Cell Res. 21, 1534-1550. doi: 10.1038/cr.2011.83

Wang, F., Wang, A. Y., Chesnelong, C., Yang, Y., Nabbi, A., Thalappilly, S., et al. (2018). ING5 activity in self-renewal of glioblastoma stem cells via calcium and follicle stimulating hormone pathways. Oncogene 37, 286-301. doi: 10.1038/onc.2017.324

Wang, J., Fu, X., Zhang, D., Yu, L., Li, N., Lu, Z., et al. (2017a). ChAT-positive neurons participate in subventricular zone neurogenesis after middle cerebral artery occlusion in mice. Behav. Brain Res. 316, 145-151. doi: 10.1016/j.bbr. 2016.09.007

Wang, J., Lu, Z., Fu, X., Zhang, D., Yu, L., Li, N., et al. (2017b). Alpha7 nicotinic receptor signaling pathway participates in the neurogenesis induced by ChAT-positive neurons in the subventricular zone. Transl. Stroke Res. doi: 10.1007/s12975-017-0541-7 [Epub ahead of print].

Wang, J., Xu, C., Zheng, Q., Yang, K., Lai, N., Wang, T., et al. (2017c). Orail, 2, 3 and STIM1 promote store-operated calcium entry in pulmonary arterial smooth muscle cells. Cell Death Discov. 3:17074. doi: 10.1038/cddiscovery. 2017.74

Wee, S., Niklasson, M., Marinescu, V. D., Segerman, A., Schmidt, L., Hermansson, A., et al. (2014). Selective calcium sensitivity in immature glioma cancer stem cells. PLoS One 9:e115698. doi: 10.1371/journal.pone. 0115698

Weiss, S., Dunne, C., Hewson, J., Wohl, C., Wheatley, M., Peterson, A. C., et al. (1996). Multipotent CNS stem cells are present in the adult mammalian spinal cord and ventricular neuroaxis. J. Neurosci. 16, 7599-7609. doi: 10.1523/JNEUROSCI.16-23-07599.1996

Westerlund, U., Svensson, M., Moe, M. C., Varghese, M., Gustavsson, B., Wallstedt, L., et al. (2005). Endoscopically harvested stem cells: a putative method in future autotransplantation. Neurosurgery 57, 779-784.

Xing, Y. L., Röth, P. T., Stratton, J. A. S., Chuang, B. H. A., Danne, J., Ellis, S. L., et al. (2014). Adult neural precursor cells from the subventricular zone contribute significantly to oligodendrocyte regeneration and remyelination. J. Neurosci. 34, 14128-14146. doi: 10.1523/JNEUROSCI.3491-13.2014

Yáñez, M., Gil-Longo, J., and Campos-Toimil, M. (2012). Calcium binding proteins. Adv. Exp. Med. Biol. 740, 461-482. doi: 10.1007/978-94-0072888-2_19

Yoast, R. E., Emrich, S. M., Zhang, X., Xin, P., Johnson, M. T., Fike, A. J., et al. (2020). The native ORAI channel trio underlies the diversity of $\mathrm{Ca}^{2+}$ signaling events. Nat. Commun. 11:2444. doi: 10.1038/s41467-020 $-16232-6$

Yoo, S., and Blackshaw, S. (2018). Regulation and function of neurogenesis in the adult mammalian hypothalamus. Prog. Neurobiol. 170, 53-66. doi: 10.1016/j. pneurobio.2018.04.001

Young, S. Z., Platel, J.-C., Nielsen, J. V., Jensen, N. A., and Bordey, A. (2010). $\mathrm{GABA}_{\mathrm{A}}$ increases calcium in subventricular zone astrocyte-like cells through L- and T-type voltage-gated calcium channels. Front. Cell. Neurosci. 4:8. doi: $10.3389 /$ fncel.2010.00008

Yuan, J. P., Zeng, W., Huang, G. N., Worley, P. F., and Muallem, S. (2007). STIM1 heteromultimerizes TRPC channels to determine their function as store-operated channels. Nat. Cell Biol. 9, 636-645. doi: 10.1038/ncb1590

Zarco, N., Norton, E., Quiñones-Hinojosa, A., and Guerrero-Cázares, H. (2019). Overlapping migratory mechanisms between neural progenitor cells and brain tumor stem cells. Cell. Mol. Life Sci. 76, 3553-3570. doi: 10.1007/s00018-01903149-7

Zeniou, M., Fève, M., Mameri, S., Dong, J., Salomé, C., Chen, W., et al. (2015). Chemical library screening and structure-function relationship studies identify bisacodyl as a potent and selective cytotoxic agent towards quiescent human glioblastoma tumor stem-like cells. PLoS One 10:e0134793. doi: 10.1371/journal.pone.0134793

Zhang, Y., Cruickshanks, N., Yuan, F., Wang, B., Pahuski, M., Wulfkuhle, J., et al. (2017). Targetable T-type calcium channels drive glioblastoma. Cancer Res. 77, 3479-3490. doi: 10.1158/0008-5472.CAN-16-2347

Zhang, R., Zhang, Z., Wang, L., Wang, Y., Gousev, A., Zhang, L., et al. (2004). Activated neural stem cells contribute to stroke-induced neurogenesis and neuroblast migration toward the infarct boundary in adult rats. J. Cereb. Blood Flow Metab. 24, 441-448. doi: 10.1097/00004647-200404000 $-00009$

Zhao, D., Najbauer, J., Garcia, E., Metz, M. Z., Gutova, M., Glackin, C. A., et al. (2008). Neural stem cell tropism to glioma: critical role of tumor hypoxia. Mol. Cancer Res. 6, 1819-1829. doi: 10.1158/1541-7786.MCR-08-0146

Conflict of Interest: The authors declare that the research was conducted in the absence of any commercial or financial relationships that could be construed as a potential conflict of interest.

Copyright $\odot 2020$ Coronas, Terrié, Déliot, Arnault and Constantin. This is an open-access article distributed under the terms of the Creative Commons Attribution License (CC BY). The use, distribution or reproduction in other forums is permitted, provided the original author(s) and the copyright owner(s) are credited and that the original publication in this journal is cited, in accordance with accepted academic practice. No use, distribution or reproduction is permitted which does not comply with these terms. 